\title{
A review of molecular dynamics simulations in the designing of effective shale inhibitors: application for drilling with water-based drilling fluids
}

\author{
Rogers Evarist Swai ${ }^{1}$ (D)
}

Received: 22 June 2020 / Accepted: 11 September 2020 / Published online: 21 September 2020

(c) The Author(s) 2020

\begin{abstract}
When drilling for oil and gas, maintaining wellbore stability is of primary importance to reduce non-productive time and trouble cost. Shale swelling causes many problems related to stability when drilling with water-based drilling fluids (WBDF). For many years, it remains the number one cause of time wastage and well abandonment. Different shale samples have different chemical compositions that affect their behavior when in contact with water. This factor makes laboratory-based analysis and characterization of the swelling mechanisms and action of swelling inhibitors extremely challenging. Moreover, the need to replicate different conditions at which clay-water interactions might occur necessitates using a different technique. Molecular dynamics (MD) simulation can be used as a supplement technique to help interpret experimental studies, test and improve a theoretical model, and provide empirical data in high-pressure and high-temperature condition of the borehole. MD simulation applies Newton's second law of motion to describe particles' movement in a classical system. The technique can be performed on the time scale of nanoseconds, and in three dimensions, it is thus sufficient for the study of clay-water interaction at a molecular level. It provides a unique view of the clay mineral interlayer and surface activities. This work reviews the progress in MD simulations of clay swelling and its inhibition mechanisms for application in petroleum drilling operations.
\end{abstract}

Keywords Clay swelling $\cdot$ Inhibitor $\cdot$ Montmorillonite $\cdot$ Molecular dynamics $\cdot$ Shale

\section{Introduction}

\section{Background}

Shales are sedimentary rocks in marine basins, composed mainly of mud, silts, and clays. Although burial depth and tectonic stresses may alter their composition in different ways (Gholami et al. 2018), the term shale refers to all kinds of clay-rich sedimentary rocks in its simplicity. They are the most abundant kind of sedimentary rocks, accounting for well over $40 \%$ of the stratigraphic column (Al-Ani and Sarapaa 2008). Because of that, when drilling oil and gas wells, most of the time is spent penetrating through

Rogers Evarist Swai

rogersswai@icloud.com;

rogers.evarist.swai@etu.univ-poitiers.fr

1 HydrASA Laboratory-IMACS, University of Poitier, 86022 Poitiers, France shales. Shale formations are responsible for over $90 \%$ of all wellbore instability cases in drilling operations (Chen et al. 2003; Gholami et al. 2018). The term clay refers to a natural material made up of powdery minerals and is usually plastic at appropriate hydration state and hardens when put to dry (Al-Ani and Sarapaa 2008; Ray 2013). Clay minerals are phyllosilicate minerals that impart plasticity to clay and account for about 50 to $60 \mathrm{wt}$. $\%$ of most shales. These minerals find use in a great range of applications and are likely the most utilized minerals.

In the petroleum industry, clay minerals are used together with other additives to prepare WBDF. However, drilling with WBDF comes with its share of challenges. It causes swelling of the drilled formation through the absorption of water by the clay minerals, necessitating inhibitor additives in the drilling fluid. Some clay minerals, such as the sodiummontmorillonite (Na-Mt), exhibit a high tendency to swell upon hydration (Salles et al. 2008). They can exceed up to ten times their original sizes (Fink 2012; Taylor and Smith 1986). While such characteristics might be of great value 
in applications such as a repository of radioactive wastes (Kaufhold et al. 2015), in the petroleum industry, the swelling of clay minerals brings wellbore stability problems with severe consequences (Anderson et al. 2010). The issues may include: below standard hole cleaning, stuck pipe, lost circulation, wellbore tightening, and well caving-in, naming just a few. Wellbore stability problems bring unwanted effects such as drilling delays, the occurrence of life-threatening accidents, loss of equipment, and even well abandonment (Moussa et al. 2017; Tan et al. 1996; van Oort 2003). The high cost of dealing with such situations makes research on wellbore stability an essential aspect of the petroleum industry. In addition to that, the increase in offshore activities in recent years has raised concerns over the ecological effects of the chemicals used in drilling operations (Fraser 2014; Pappworth and Caudle 2016; Zhang et al. 2016a). Worldwide, there are over 12,000 active offshore installations (Ars and Rios 2017). Across the globe, researchers are working on finding organic solutions to clay swelling and its related problems of wellbore instability.

Advancement in computer power and fast algorithms have given researchers an insight into the molecular world of particles in clay-water-inhibitor system interactions and the involved mechanisms behind clay swelling inhibition (Boek et al. 1995a; Moussa et al. 2017). This insight has enabled the identification of molecules that meet the requirements of environment conservation (Pappworth and Caudle 2016; Zhang et al. 2016a) and at the same time, capable of efficiently inhibit swelling, satisfying the requirements of the petroleum industry (Hodder et al. 2010; Suter et al. 2011; Zhong et al. 2013).

\section{Overview of computer simulations}

Computer simulation techniques have become extremely useful, if not essential, to understand the underlying principles behind clay swelling in clay-water systems and determine the mechanism behind its inhibition in clay-water-inhibitor systems. The simulations can reveal both the interlayer structure and the dynamics of clay minerals and the full swelling potential and its entropic and energetic components (Anderson et al. 2010). Thus, the computer simulations allow for a clear correlation between clay structure and swelling thermodynamics to be determined. Two families of computer simulations are employed in the studies, quantum mechanics and statistical mechanics, whereby the involved techniques are: computational quantum chemistry (CQC), molecular mechanics (MM), molecular dynamics (MD), and Monte Carlo (MC) simulation. Before looking at the MD simulation technique, it is vital first to understand the basics of clay swelling and have a general understanding. The remaining sections of this chapter are dedicated to the literature that covers just that.

\section{Clay swelling}

Swelling of clay occurs in the presence of water when interlayer cations acquire several hydration layers and force the clay layers apart. There is no single theory that describes the swelling of clay (Fig. 1). Over the years, researchers have come up with several ideas to explain the clay swelling mechanism, but only two have become widely accepted. Pioneering works in 1952 by Mooney et al. (1952) and in 1954 by Norrish (1954) have shown that clay minerals swell via crystalline and osmotic patterns.

(1) Crystalline swelling

Crystalline swelling is a process whereby water layers are intercalated between individual 2:1 silicate layers (Laird 2006). The process by which the water layer accumulates in clay interlayer is discrete, which forms a one-, two-, and three-layer (sometimes up to four- and five-layer) hydrates. The forming of hydrate layers inside Mt interlayer space results in an increased interlayer separation (Boek et al. 1995b; Chavez-Paez and dePablo 2001; Norrish 1954). The
Fig. 1 A cartoon of water intercalation into Na-Mt model (a) and swelling, $d_{2}>d_{1}(\mathbf{b})$

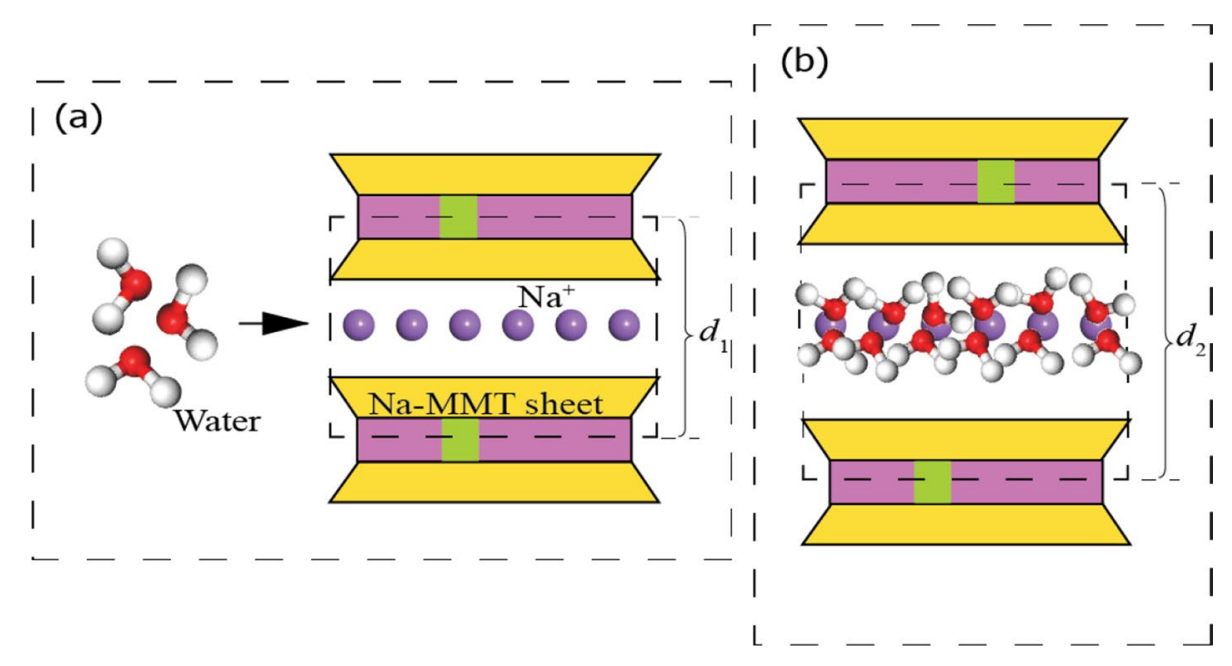


range of typical interlayer separation in the crystalline swelling regime is from 9 to $20 \AA$ (Nehdi 2014). The compaction pressures for dehydration for the last layer and the second layer of water molecules are about 70,000 and 25,000 psi ( $\sim 480$ to $\sim 170 \mathrm{MPa}$ ) (Olphen 1962). Studies have shown, up to a depth of $10,000 \mathrm{ft}(\sim 3 \mathrm{~km})$, the formation is dominated by clay-rich sediments with a fair composition of smectites but reduces rapidly past this value (Bjørlykke 1998; Brown et al. 2017; Hower et al. 1976), at such a depth, the significant stress is $<5000 \mathrm{psi}(\sim 30 \mathrm{MPa})$ (Wang 2010). However, it is crucial to have in mind that the non-swelling clay minerals, such as illites in deep intervals, will exhibit swelling if they were formed from the smectites transformation (Fink 2012). For drilling environments, in shale, the first several layers of water molecules always exist. Crystalline swelling is, therefore, insignificant to drilling and can occur in all types of clay minerals.

\section{(2) Osmotic swelling}

Osmotic swelling is the second type of swelling where the concentration of cations between unit layers in a clay mineral is higher than that in the surrounding water. Water is drawn osmotically between the unit layers, and the interlayer spacing increases. This type of swelling can increase interlayer spacing from 20 up to $130 \AA$ resulting in a considerable volume increase (Nehdi 2014). Osmotic swelling results in more massive overall volume increases than crystalline swelling, but only a few minerals, like $\mathrm{Na}-\mathrm{Mt}$, swell in this manner (Fink 2012). Smectite clay saturated with potassium cations $\left(\mathrm{K}^{+}\right)$does not swell in this manner and forms only crystalline hydrates in aqueous suspension (Posner et al. 1963). $\mathrm{K}^{+}$saturated Mt's behavior explains why potassium chloride $(\mathrm{KCl})$ has been referred to as the best inorganic salt shale inhibitor in petroleum drilling. It controls the swelling and hydration through the cation exchange reaction between the $\mathrm{K}^{+}$and the clay (Suter et al. 2011).

\section{Montmorillonite clay minerals}

Mt is a common clay mineral named after Montmorillon town in France, which was discovered in 1847 (AnnabiBergaya 2006). It is the main constituent of bentonite that is usually used in the drilling fluid. The Mt is a member of the smectite group with two tetrahedral sheets sandwiching a central octahedral sheet (Wang 2010). It has a crystallographic structure based on the pyrophyllite model (Fig. 2). The isomorphic substitution of atoms in its lattice renders a permanent overall negative charge of the layers, which gives it the ability to absorb certain cations and retain them in an exchangeable state. This property makes it possible for the intercalated cations to be exchanged by other cations in a water solution.

For Mt's physical characteristics, one can visit the work of Ray (2013). This paper's structure is thus: the first chapter presented a background on shale, clay, and clay minerals and their associated problems when drilling with WBDF. Besides, it provided an overview of computer simulations and the roadmap for carrying out a typical MD simulation of clay hydration and swelling. The second chapter lays out the MD simulations requirements and reviews literature that describes the parameters involved in the technique and the progress made in the last two decades. In the third chapter, the different documented literature that suggests clay
Fig. 2 A schematic illustration of the layered crystallographic structure of Mt

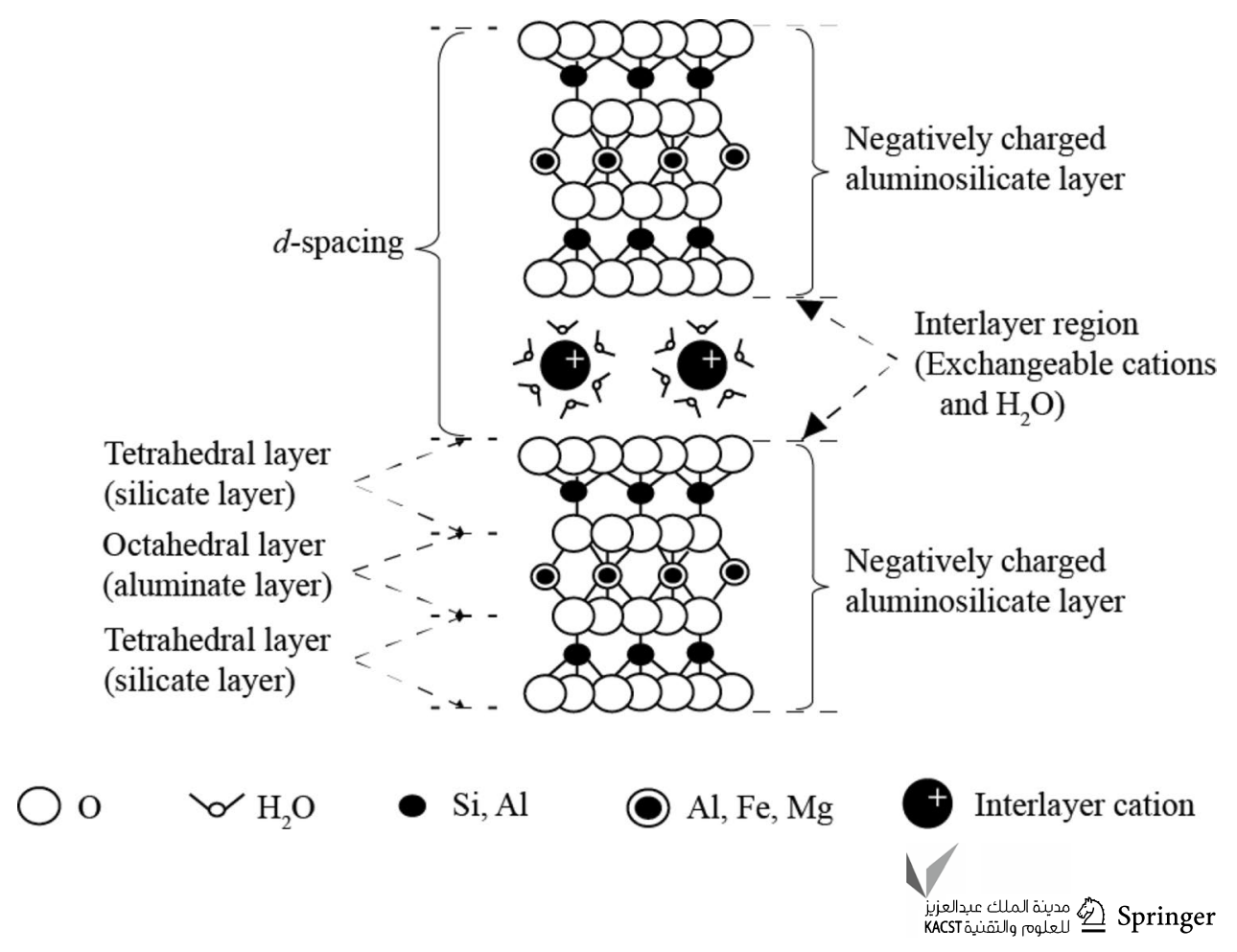


swelling mechanisms and its crystal structure-property are reviewed. Chapter four presents selected literature on the action of inhibitors in preventing clay swelling. Lastly, chapter five gives an outlook on the future of MD simulations in investigating clay-water-inhibitor interactions.

\section{Molecular dynamics simulation}

In any MD simulation system, interaction energies will depend on the potential function forms, the force field parameters, and the thermodynamic ensembles used. Figure 3 shows a typical flow plan for modeling and MD simulation of the clay-water-inhibitor interactions system. The ever-improving molecular simulation techniques and increasing accuracy of the potential energy parameters provide researchers a wide field of endeavor with limitless possibility. In the present section, we are going to introduce the MD simulation technique briefly.

\section{Thermodynamics states}

Any thermodynamics system has state variables that describe its macroscopic states, which are the number of particles $(\mathrm{N})$, volume $(\mathrm{V})$, temperature $(\mathrm{T})$, pressure $(\mathrm{P})$, total energy $(E)$, and chemical potential $(\mu)$. In molecular simulations, some state variables are external parameters, while others are observables that need to be calculated. The following are the thermodynamic states commonly employed in MD simulations. (1) Microcanonical ensemble (NVE), where a change $\mathrm{N}, \mathrm{V}$, and $\mathrm{E}$ is isolated as the external parameters, and $\mathrm{T}$ and $\mathrm{P}$ are the observables to be calculated. NVE

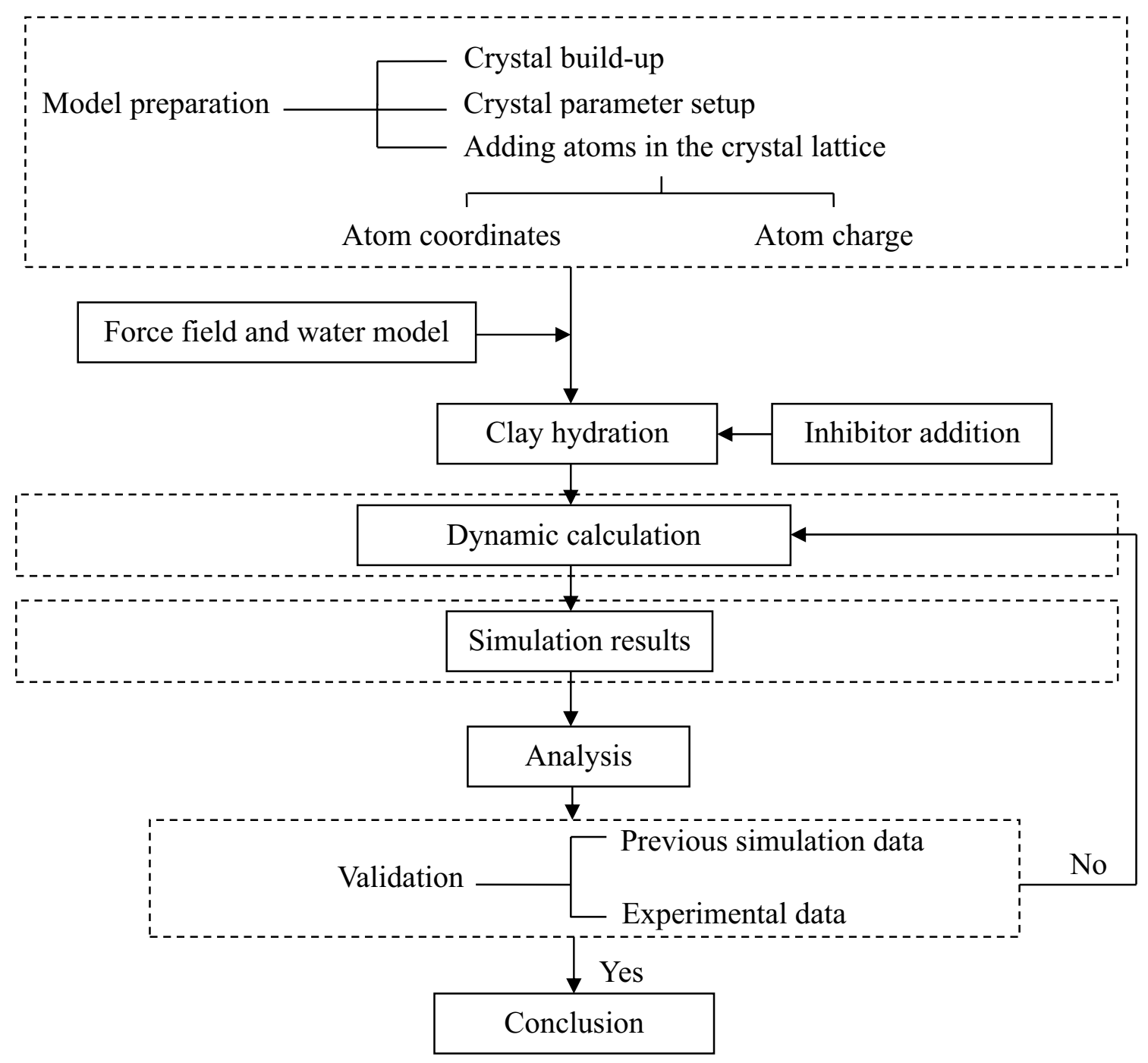

Fig. 3 A typical molecular dynamics simulation steps for studying clay hydration and swelling 
can be used to test the adequacy of a time step by checking the conservation of total energy (Rappe et al. 1992). (2) Canonical ensemble (NVT) (also called constant temperature molecular dynamics (CTMD)). In NVT, E and P are the observables to be calculated. The use of an NVT ensemble requires a thermostat (common ones are Nose-Hoover, the Berendsen, and the Andersen thermostats) to keep the temperature constant by adding or removing energy into the system. (3) Isobaric-isothermal (NPT) ensemble differs from NVT dynamics in that it requires a barostat in addition to the thermostat. (4) Grand canonical ( $\mu \mathrm{VT}$ ) ensemble considers simulations with a varying number of particles. In $\mu \mathrm{VT}$, the system is enclosed in a permeable container that allows adding or removing particles while keeping $\mathrm{V}, \mathrm{T}$, and $\mu$ constant.

\section{Periodic boundary condition}

MD simulations employ periodic boundary conditions (PBC) for a finite system to represent particles' interaction in an infinite real-life environment. PBC approximates an infinite system by replicating the simulation box in all directions, producing the original unit cell's images. A truncation is applied by introducing cut-off distance $\left(r_{c}\right)$ to avoid particles interacting with their images. Usually, the $r_{c}$ is chosen that $r_{c} \leq \frac{L}{2}$, where $L$ is the diameter of the periodic box (Frenkel and Smit 2002). Additionally, all systems containing electrostatic interactions must be charge-neutral to avoid infinite charge generation when replicated.

\section{Force field}

A force field refers to the functional form and parameter sets describing the dependence of a system's energy on the coordinates of its particles (González 2011). Since the 1960s when we saw the first application of force fields, several force fields have been developed. The Universal force field (uff) is a generic force field by Rappe et al. (1992), the consistent valence force field (cvff) by Roberts et al. (1988), and the clay force field (Clayff) by Cygan et al. (2004). The Clayff was explicitly developed to describe clay-water interactions. These four are the most commonly used force fields in clay-water system interactions. It is important to remember that any MD simulation results are mostly dependent on the force field used. The availability of different force fields to choose from and the possibility to combine two or more guarantee the most reliable results.

\section{Water model}

Many models have been proposed to represent water, but mainly four are repeatedly used in clay-water and clay-water-inhibitor system interactions: SPC (simple point charge) (Berendsen et al. 1981), TIP4P (four-point transferable intermolecular potentials) (Jorgensen and Madura 1983), MCY (O. Matsuoka, E. Clement, and M. Yoshimine) (Neumann 1985), and SPC/E (extended simple point charge) (Berendsen et al. 1987) water-based models (Fig. 4).

\section{Montmorillonite-water interactions}

\section{Swelling mechanisms of Mt}

When drilling with WBDF through shale formation, water penetrates the clay interlayer and causes it to swell by forming several water layers in a stepwise fashion. However, this way of swelling is not a concern for the petroleum drilling engineers; it only becomes a problem when excess water gets in the formation by the interlayer cations' osmotic action. The cations usually attract more water than the clay surface leading to swelling past the crystalline regime (> $20 \AA$ basal spacing increase). In the following sub-sections, we review the MD simulations that explain the possible mechanisms of Mt swelling.

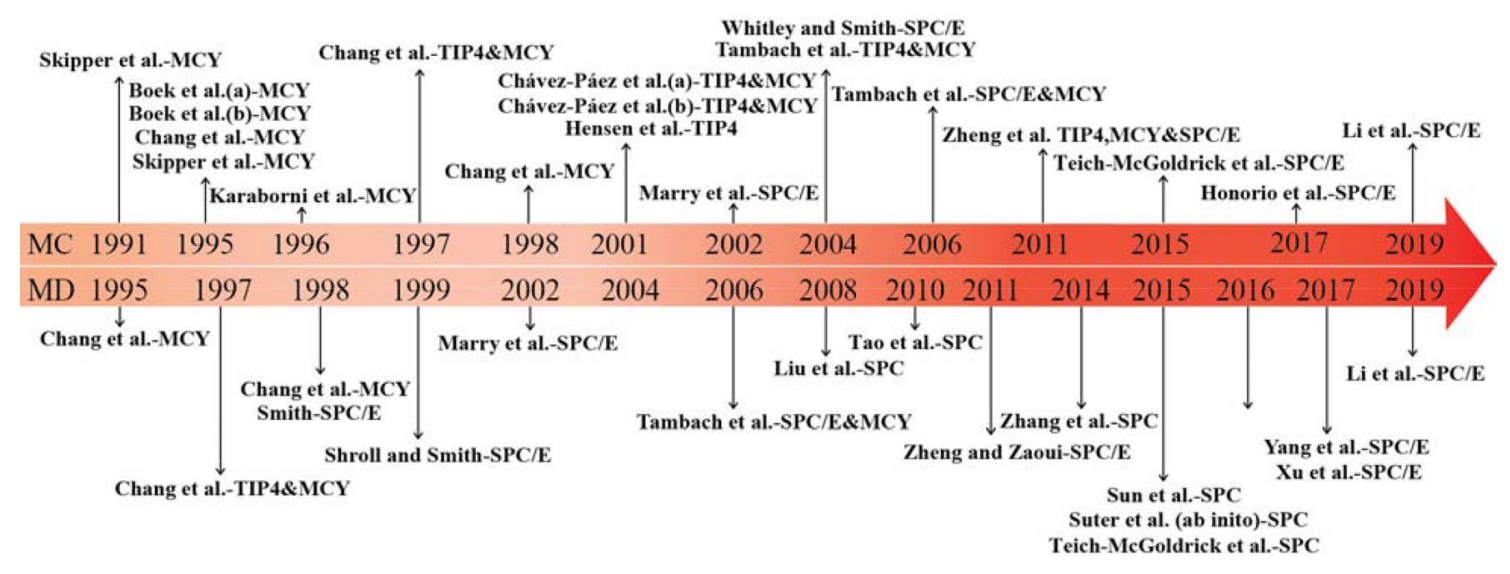

Fig. 4 The timeline of different molecular simulations with the used water-based models 


\section{Effect of water content}

It is known that clays swell through transitional phases between discrete layer hydration states. The water content is directly linked to the swelling of clay minerals as the equilibrium hydration states inside the interlayer space of clay minerals increase interlayer separation. With increasing uptake of water by the clay mineral, there will be the formation of water layers in the interlayer region (Berendsen et al. 1987; Georg et al. 2008; Katti et al. 2009; Shroll and Smith 1999; Yang et al. 2017; Zhang et al. 2014). Additionally, water content is related to forming two types of surface complexes, the inner- and outer-sphere complexes. As shown in Fig. 5, at low water content, the interlayer cations form inner-sphere surface complexes with the oxygen of the clay sheet and oxygen of the water molecule. However, at high water content, outer-sphere surface complexes are formed when a part of the innersphere surface complexes break from the clay surface and move in the interlayer's central plane (Hensen and Smit 2002). The loss of coordination to the surface increases the diffusion rates of the interlayer cations. This transition takes place because of the increase in interlayer separation and the number of intercalated water molecules. The inner- and outer-sphere surface complexes will co-exist in all the layer hydrates (Bourg and Sposito 2010; Chang et al. 1995, 1997, 1998).

Therefore, as Sun et al. (2015) have shown it (Fig. 5), the increase in water content increases interlayer cations coordination, which adversely increases the Mt water uptake capability and swelling.

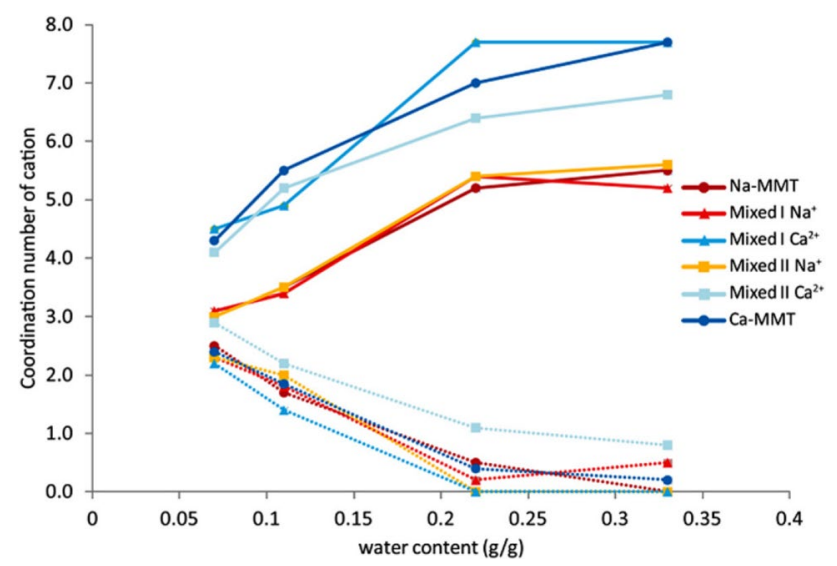

Fig. 5 Coordination numbers of interlayer cations to the clay oxygen atoms (dotted lines) and water oxygen atoms (solid lines) for $\mathrm{Na}-\mathrm{Mt}$, Mixed I, Mixed II, and Ca-Mt as a function of water content (Sun et al. 2015)

\section{Effect of type of interlayer cation}

Effect of charge of interlayer cation The valence of interlayer cation strongly influences clay mineral-water interactions (Na and Zhang 2006; Tao et al. 2010; Wu et al. 2015). The monovalent cations have low coulombic interactions with other interlayer particles compared to the higher valence cations (Zheng and Zaoui 2011). Zhang et al. (2016b) investigated the differences in the crystalline swelling regime of $\mathrm{Na}-$ and $\mathrm{Ca}-\mathrm{Mt}$. They showed that $\mathrm{Ca}-\mathrm{Mt}$ had more substantial hydration swelling in the crystalline swelling than $\mathrm{Na}-\mathrm{Mt}$ due to $\mathrm{Ca}^{2+}$ forming large and stable hydration rings than $\mathrm{Na}^{+}$. However, Tao et al. (2010) showed that $\mathrm{Na}-\mathrm{Mt}$ overall swelling was higher than that of $\mathrm{Ca}-\mathrm{Mt}$ and $\mathrm{K}-\mathrm{Mt}$. Still, however, it is essential to note that the higher the valence, the higher the cation's hydration energy (Hensen et al. 2001; Li et al. 2019; Seppälä et al. 2016).

Accordingly, from these results, one can deduce that the crystalline swelling extent follows a well-known order for different Mt (Fig. 6). The hydration of the interlayer cation increases with the valence, so is the Mt swelling.

Effect of size of interlayer cation Studies have shown that the size of the cation influences its residency. Hensen et al. (2001) studied adsorption isotherms of water in $\mathrm{Li}-, \mathrm{Na}-$ and $\mathrm{K}-\mathrm{Mt}$. They found that the big sized $\mathrm{K}^{+}$mainly resided in the interlayer region, the small-sized $\mathrm{Na}^{+}$, and $\mathrm{Li}^{+}$organized in double layers close to the clay surface. However, the works of Moussa et al. 2017, Wu et al. 2015, and Xu et al. 2017 contradicted this observation. Their results have shown that bigger sized cations such as $\mathrm{K}^{+}$and $\mathrm{Cs}^{+}$tended to sink into the hexagonal cavity and become immobilized. However, despite the contradiction, both simulations can be correct. The interlayer cation residency depends on the total simulation time and how long the system was allowed to stay in equilibrium before doing calculations. Additionally, from the production's trajectories, the mean residency time of the cations at each location in the interlayer space can be obtained and indicate the preferred residency.

Whitley and Smith (2004) computed disjoining pressure for $\mathrm{Na}-, \mathrm{Sr}-$ and $\mathrm{Cs}-\mathrm{Mt}$ and revealed that at the smallest interlayer spacing, Cs-Mt pressure was greater than that of $\mathrm{Na}-$ and $\mathrm{Sr}-\mathrm{Mt}$ because of the bigger sized $\mathrm{Cs}^{+}$. These variations in disjoining pressure that decomposed into energetic and entropic components led to different swelling free energies of the clays. In another study by Marry et al. (2002), Cs-Mt registered higher diffusion coefficients than $\mathrm{Na}-\mathrm{Mt}$ because

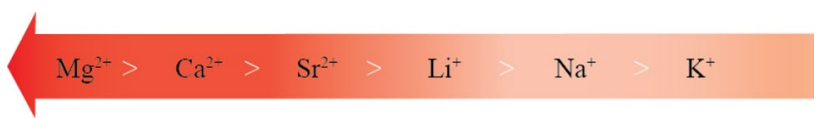

Fig. 6 Charge influence on the hydration of interlayer cation 
$\mathrm{Cs}^{+}$was less hydrated than $\mathrm{Na}^{+}$, which led to its high diffusion degree. The hydrated radii from their work agreed well with those reported by Zheng and Zaoui (2011) (Fig. 7). The reported MD simulations hydrated radii seem to propose that Mt saturated with smaller sized counterions will swell more than those saturated with larger ones.

Effect of migration and residency of interlayer cation The mobility of interlayer particles, especially the counterions, impacts Mt's swelling pressure (Sun et al. 2016), an essential quantitative indication of expansive clays' swelling potential. The swelling pressure is the maximum normal force applied to soil in contact with an external solution to maintain a constant volume. The increase in interlayer particle mobility increases Mt interlayer's swelling pressure, leading to more swelling. The mobility of a particle in the interlayer region is dependent on the type of the particle and the confinement of the Mt surfaces (Marry et al. 2002; Ngouana et al. 2014; Zhang et al. 2014).

The residence of interlayer cation determines its degree of hydrations and the consequent swelling extent of Mt. The formation of outer-sphere complexes increases the hydration degree of interlayer cations. The outer-sphere surface complexes will start to form after two-layer hydrate when more water molecules are intercalated. In one-layer hydrate, interlayer cation will interact with the clay surface's oxygen to form inner-sphere surface complexes. Zhang et al. (2014) also found that water spends a long time in the cation's hydration shell than in bulk. Boek et al. (1995b) investigated Wyoming Mt with $\mathrm{Li}^{+}, \mathrm{Na}^{+}$, and $\mathrm{K}^{+}$counterions. Analyzing the interlayer structure, they found that both $\mathrm{Li}^{+}$and $\mathrm{Na}^{+}$detach from the clay surface and migrate to the interlayer region where they hydrate, agreeing with observation reported by Chávez-Páez et al. (2001). On the other hand, the $\mathrm{K}^{+}$migrates and binds to the clay surface, making it difficult to hydrate. The present literature suggests that when cations migrate to the interlayer's mid-plane, they tend to hydrate more and cause significant Mt swelling than when they stay close to the surface. However, as necessary

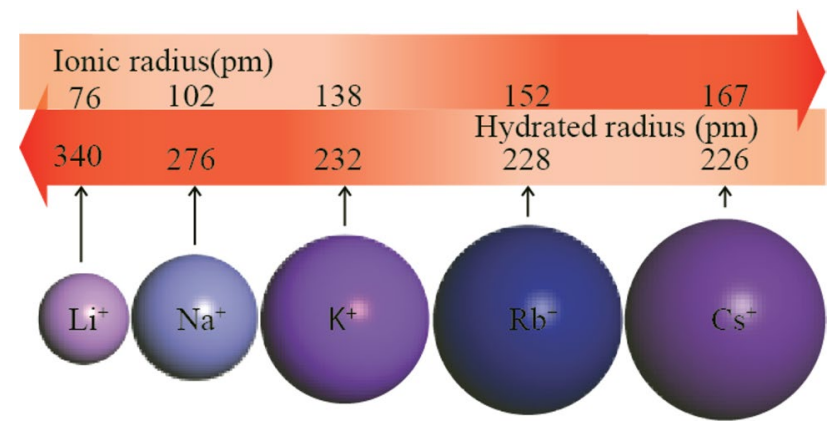

Fig. 7 Ionic radius influence on cation hydration; values adapted from Zheng and Zaoui (2011) as this might be to understand clay swelling, there are still contradictions on interlayer cations' actual residency from several reported findings (visit sub-section "Effect of size of interlayer cation"). Therefore, further MD simulations should be conducted to clarify where the cations are located and postulate why they choose those locations.

The hydration shell's size and stability around interlayer cation affect its ability to diffuse in the interlayer. Zhang et al. (2014) found that $\mathrm{Ca}^{2+}$ self-diffusion coefficients were lower than that of $\mathrm{Na}^{+}$due to a larger and much stable hydration shell. These results indicate that hydration has an impact on particles' diffusion in the interlayer. Furthermore, larger hydration complexes in the interlayer have fewer diffusion pathways compared to the smaller ones. Figure 8 shows the calculated diffusion coefficients from various MD simulation works.

\section{Effect of layer charge and charge substitution sites}

Layer charge and charge substitution sites can cause different swelling behavior of clay minerals (Chávez-Páez et al. 2001; Kenji et al. 2000; Liu et al. 2008; Tambach et al. 2004). Liu et al. (2008) prepared two sets of Mt models by altering charge substitution sites in the tetrahedral sheet. Their simulation results revealed that the distribution of charge sites had a minimal effect on clay swelling, consistent with Ngouana et al. (2014) results.

In another work by Tambach et al. (2004), two sets of 8 unit cell Mt models were prepared. The first set had substitutions in both octahedral and tetrahedral charge sites with a total charge of $6 \mathrm{e}$. The second set had substitutions only in octahedral with a total charge of $8 \mathrm{e}$. The results showed that interlayer cations had more affinity to Mt's surface with both tetra- and octahedral substitution than the one with only octahedral substitution. Additionally, the model with an $8 \mathrm{e}$ layer charge had more water content as eight counterions attracted more water than six counterions in the other model. Similar swelling behavior with increasing layer charge due to the significant number of interlayer cations and greater ion hydration enthalpies was reported by Yi et al. (2018). Even so, opposite claims were made by Greathouse and Sposito (1998) and Seppälä et al. (2016). They indicated that Mt with lower layer charges experiences more significant swelling than one with a higher charge. The argument was made that coulombic attractions between the negatively charged tetrahedral-octahedral-tetrahedral (TOT) layers and positively charged interlayer cations adjoin the facing layers. So, the higher the charge, the more firmly the layers are held together. However, it should also be noted if the charge is excluded from the octahedral region, the force cannot be as strong as if it was due to the tetrahedral sites (Teich-McGoldrick et al. 2015). In another study by Sun et al. (2016), the influence of layer charge and charge location on the swelling 
a)

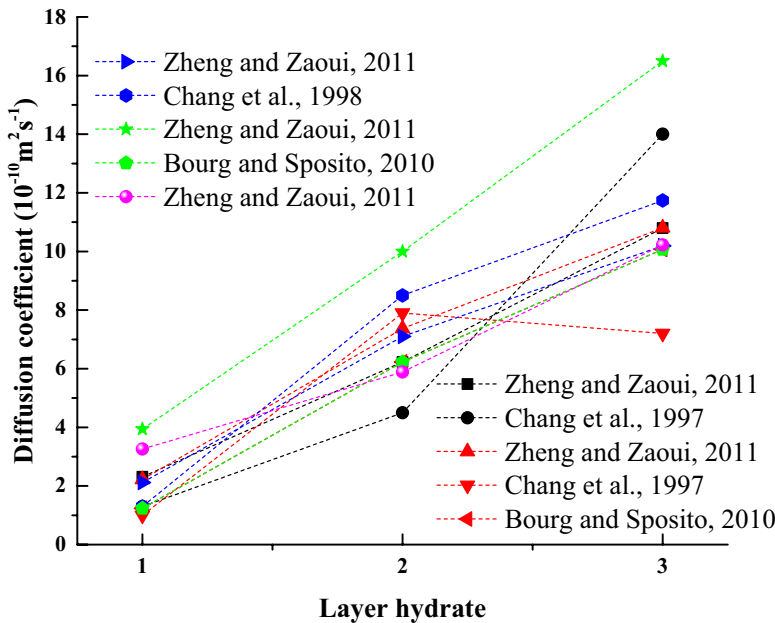

b)

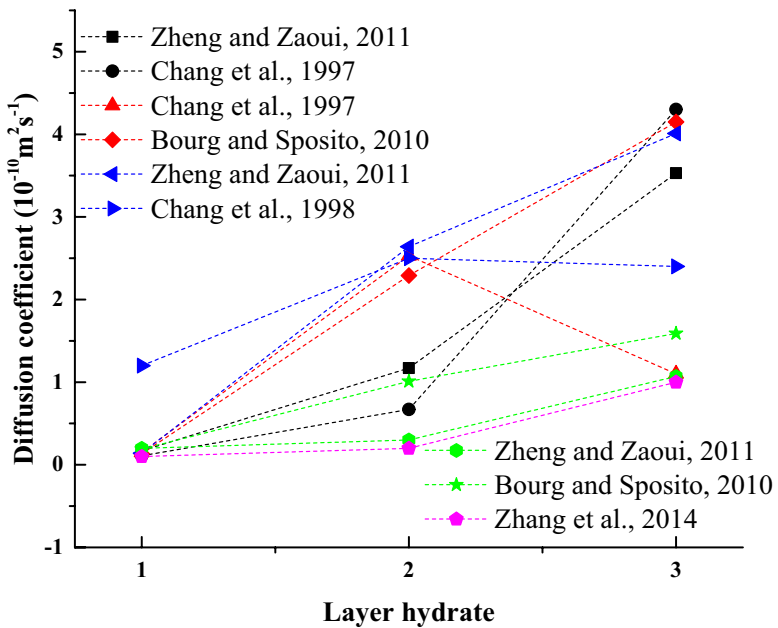

Fig. 8 Calculated diffusion coefficients for water (a) and cation (b) of Li-Mt (black), Na-Mt (red), Cs-Mt (green), K-Mt (blue), and Ca-Mt (magenta)

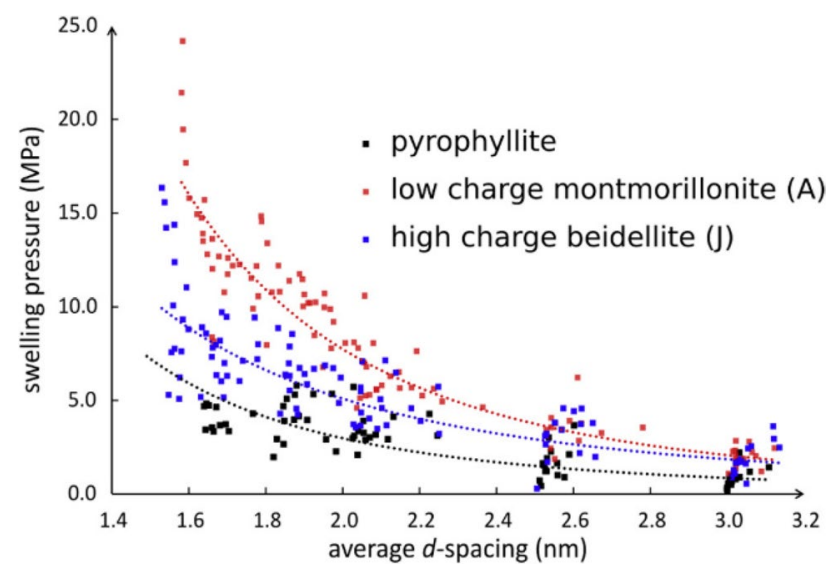

Fig. 9 Swelling pressure as a function of d-spacing for different clays (Sun et al. 2016)

pressure was found to be inversely related to the d-spacing (Fig. 9).

A 3D swelling pressure map in Fig. 10 shows the dependency of swelling pressure on the hydration state, charge magnitude, and charge location of $\mathrm{Na}-\mathrm{Mt}$.

Since atom substitution in Mt layers affects the number of balancing counter ions in the interlayer, it plays a significant role in Mt swelling (Figs. 9 and 10). As Yi et al. (2018) have reported, the interlayer exchangeable cations have more vital hydration ability than the Mt surface, indicating fewer cations will lead to less Mt water uptake and swelling. Hence, the need for more MD simulations to infer correct Mt swelling behavior and remove the prevailing contradictions on the effect of charge location and amount.

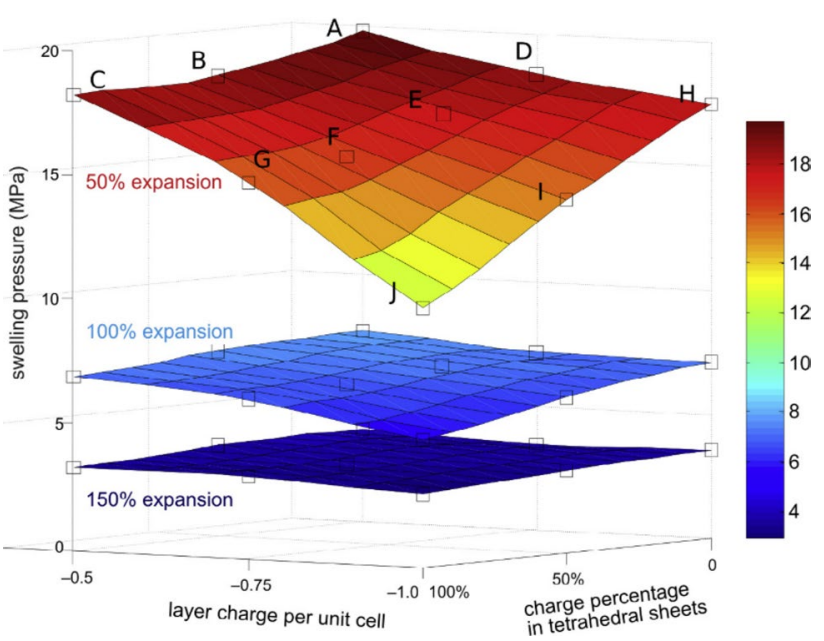

Fig. 10 Swelling pressure as a function of layer charge and charge percentage in tetrahedral sheets for $\mathrm{Na}-\mathrm{Mt}$ (Sun et al. 2016)

\section{Effect of Mt structure}

Suter and associates (2015) employed Ab initio MD simulation to investigate the interlayer and micropore structure of hydrated Mt clays. Their study showed that clay edge sites possess complex amphoteric behavior. Furthermore, the acid/base behavior was dependent on the considered face and the isomorphic substitution sites. They also found that in the tetrahedral substitutions of the clay edge (1 10$)$, the adjacent exposed apical oxygens abstracts a proton from nearby water molecule behaving as a Bronsted base, whereas, with substitution in the octahedral layer of the clay edge, instead of drawing off a proton, the exposed apical oxygen increased 
the number of hydrogen-bonded water molecules from one to two. Suter's observation has shown how complex interactions involving clay minerals can become. Therefore, more simulations that consider chemical reactions should be done to further our understanding of clay swelling.

In 2017 Guomin Yang and associates studied cation hydration in $\mathrm{Ca}-$ and $\mathrm{Na}-\mathrm{Mt}$ nanopores. They observed an increase in Mt hydrate stable states from one- to five-layer hydrates with increasing water content. In hydration states lower than the five-layer, the formation of a transient innersphere surface complex by $\mathrm{Na}^{+}$showed a strong affinity to clay ditrigonal cavities and the clay surface; however, it was not the case with Ca-Mt. Another study by Li et al. (2019) found that water mobility in the water-saturated mesopores was lower than water mobility in thin films adsorbed on the clay external basal surfaces. They thus revealed for given water content, the mobility of particles in the interlayer was lower than that from the exterior surface. Seeing that clay minerals are formed by the stacking together of clay sheets, many stacking arrangements will give rise to nanoand micropores. Hence, it is essential to understand cations' behavior in these different environments and see how they influence clay swelling.

\section{Effect of hydrogen bonding}

In 2006, Tambach and his fellows set up the simulation system to mimic clay mineral in contact with the water reservoir, imposing the water chemical potential and temperature. They found a free-energy barrier for the system to go from a one- to a two- and a three-layer hydrate that the system has first to overcome, which may cause it to stay in a meta-stable state. This finding led them to believe that the breaking and formation of hydrogen bonds within a water layer and between water molecules dominate the shrinking and swelling of clay minerals.

\section{Effect of temperature and pressure}

During petroleum drilling operations, the wellbore (Fig. 11) temperature and pressure increase at a gradient of $30^{\circ} \mathrm{C} / \mathrm{km}$ and $150 \mathrm{bar} / \mathrm{km}$ down the wellbore, respectively (Anderson et al. 2010; Bjørlykke 1998). By studying the interlayer spacing of $\mathrm{Na}-, \mathrm{Ca}-$, and $\mathrm{Na} / \mathrm{Ca}-\mathrm{Mt}$, Sun et al. 2015 showed an increase in Mt swelling with temperature rise. The temperature effect is minimal at low water content and more pronounced at high water content. In another work, Zhang et al. (2019) observed insignificant basal spacing changes at the same water content, suggesting the basal spacing is independent of temperature.

The temperature increase does not influence the hydration energy of the interlayer cations. However, it reduces the size of hydration rings of interlayer cations by lowering the cation-water coordination (Fig. 12). The works of Moussa et al. (2017) and Sun et al. (2015) have shown that at high temperatures, water molecules gain enough energy to break free from hydration rings of cations.

Different from temperature, the swelling of $\mathrm{Mt}$ is weakly affected by pressure increase. However, Mt swelling response to pressure change is influenced by the type of interlayer cation and water content. Sun et al. (2015) showed that $\mathrm{Na}-\mathrm{Mt}$ is stable to pressure change at one- and twolayer hydrates, but $\mathrm{Ca}-\mathrm{Mt}$ begins to be stable from two-layer hydrate (Fig. 13).
Fig. 11 A schematic illustration of the changing wellbore conditions with depths. Water invades the formation (a), low temperature and low pressure near the surface (b), and high temperature and high pressure deep in the wellbore (c)

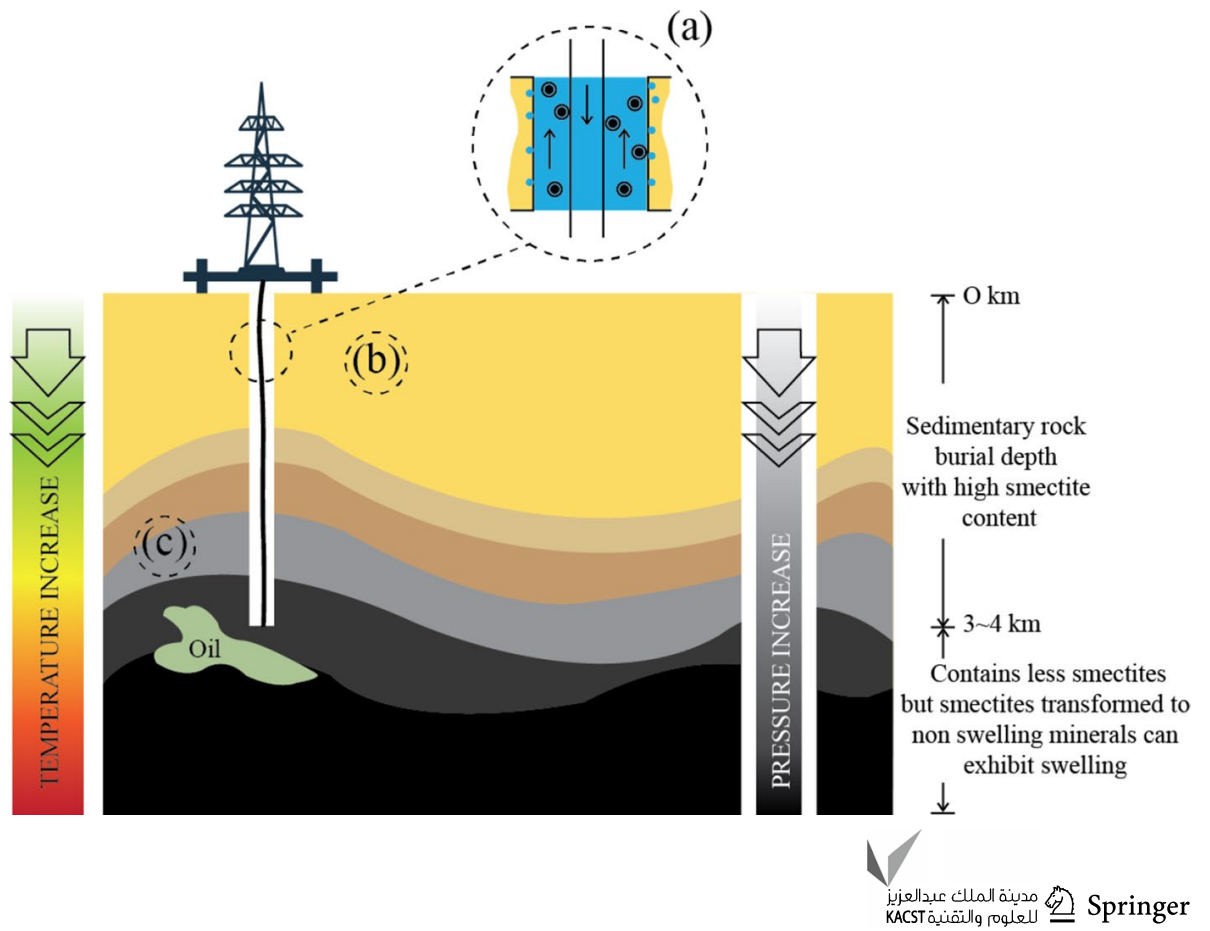



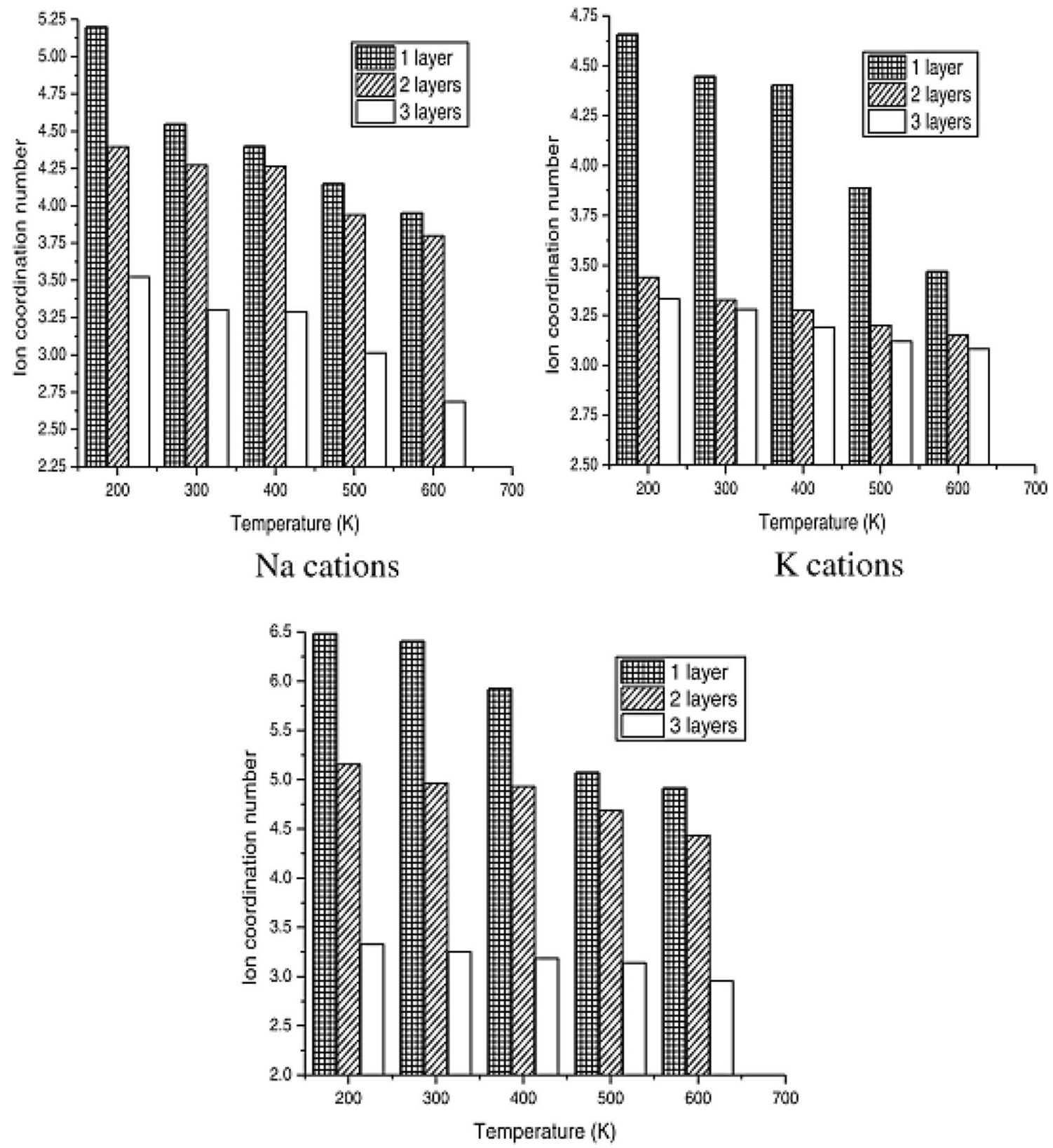

Ca cations

Fig. 12 Coordination number of interlayer cations with temperature rise (Moussa et al. 2017)

Most literature simulated clay behavior with temperature and/or pressure by fixing one while changing the other. However, as borehole drilling is concerned, they both increase with depth. Therefore, more MD simulations should be performed as it will be interesting to know how that will influence clay swelling and inhibition.

\section{Mechanical properties of montmorillonite}

Clay minerals, due to their structure, possess enormous elastic anisotropy. Some MD simulations have been conducted and provided interesting findings. For example, Sayers and Boer (2016) showed that clay's anisotropy was due to strong 
Fig. 13 The influence of pressure on the swelling of (a) $\mathrm{Na}-\mathrm{Mt}$ and (b) Ca-Mt. The deviation in d-spacing is given relative to that at $0.1 \mathrm{MPa}$. The vertical lines indicate roughly the water contents of the 1-, 2-, and 3-layer hydrates(Sun et al. 2015)
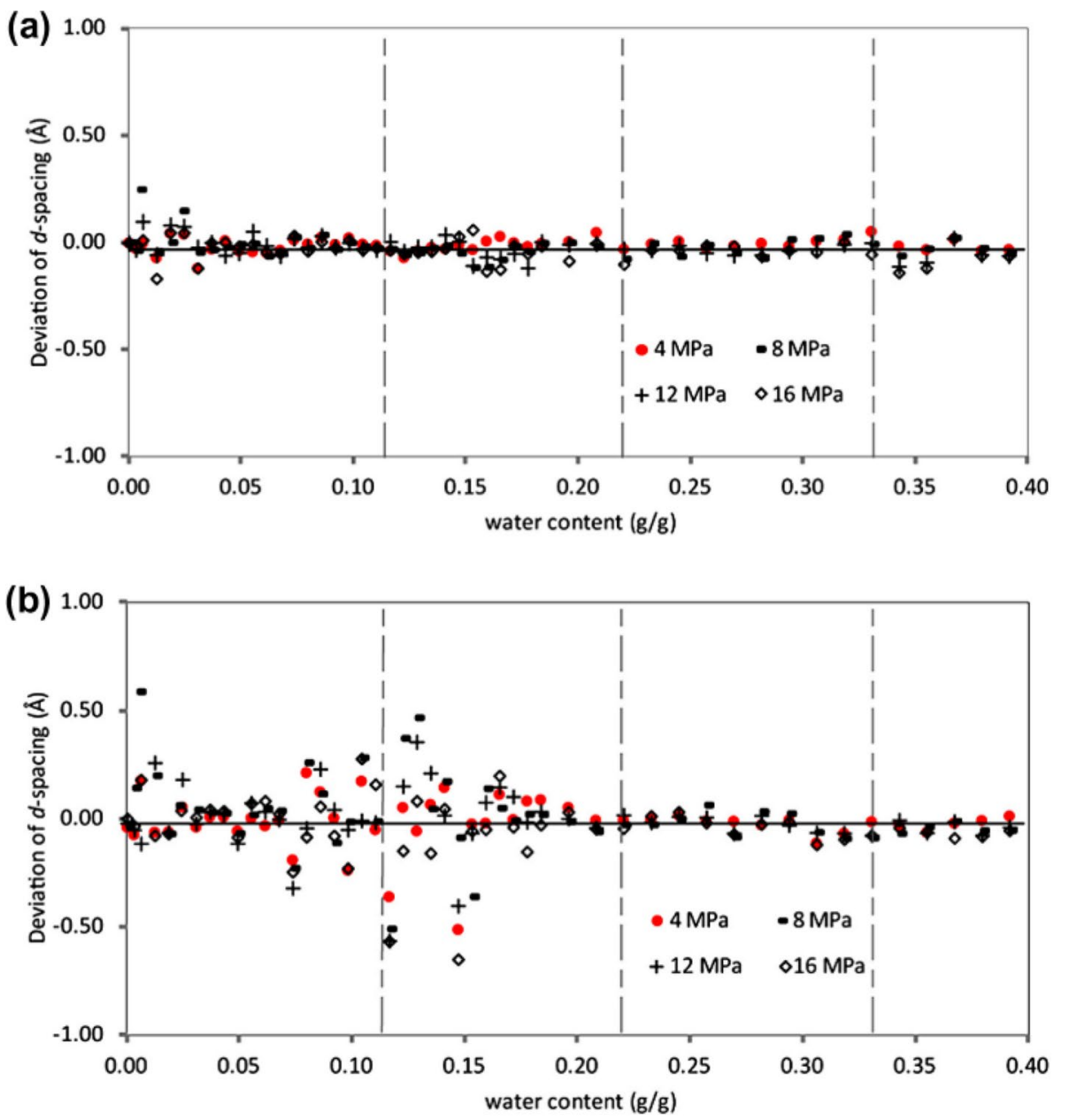

covalent bonds within layers and much weaker electrostatic bonds in between. Because of the minerals' anisotropic nature, it is nearly impossible for experiments to be conducted on a single crystal but rather clay films. However, Carrier et al. (2017) showed a significant discrepancy in how thin clay films and clay particles behaved upon hydration. This sub-section introduces some of the MD simulation studies on the elastic behavior of clay crystals and their hydro-mechanical response with increasing water content.

\section{Effect of water content}

Different researchers (Carrier et al. 2014; Katti et al. 2007; Schmidt et al. 2005; Zhang et al. 2017; Zheng and Zaoui 2018) have shown that increasing water content decreased the elastic stability of Mt crystal (Fig. 14). Mt crystal configurations changes with the process of swelling and shrinking (Zheng and Zaoui 2018). Besides, Zheng and Zaoui (2018) observed hysteresis phenomena in bulk and shear moduli during both processes.

Zhang et al. (2017) studied Na-Mt changes in mechanical properties with a variable component mixture of $\mathrm{CO}_{2}$ and water. Hydrostatically testing the system at one- and twolayer hydrates, both volume and basal spacing decreased linearly with the pressure. The gradient of the one-layer hydrate was small compared to that of the two-layer hydrate indicating the crystal is much stable at low hydration.

The mechanical behavior of shale has concerned engineers for decades, especially when clay-water interactions are anticipated. When drilling shale formations with WBDF, the borehole structural integrity is significantly impaired. Therefore, these studies are essential not only for protecting the expensive equipment but also for people working in the fields.

\section{Effect of Mt structure}

Carrier et al. (2014) studied elastic properties of swelling $\mathrm{Mt}$ and categorized their stiffness tensor results in in-plane coefficients $\left(\mathrm{C}_{11}, \mathrm{C}_{22}, \mathrm{C}_{12}\right.$, and $\left.\mathrm{C}_{66}\right)$ and out-of-plane coefficients $\left(\mathrm{C}_{33}, \mathrm{C}_{13}, \mathrm{C}_{23}, \mathrm{C}_{44}\right.$, and $\left.\mathrm{C}_{55}\right)$. They observed that Mt behaved differently depending on the crystal orientation; for instance, water content had a strong influence on the out-of-plane elastic properties than the in-plane properties.

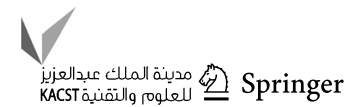



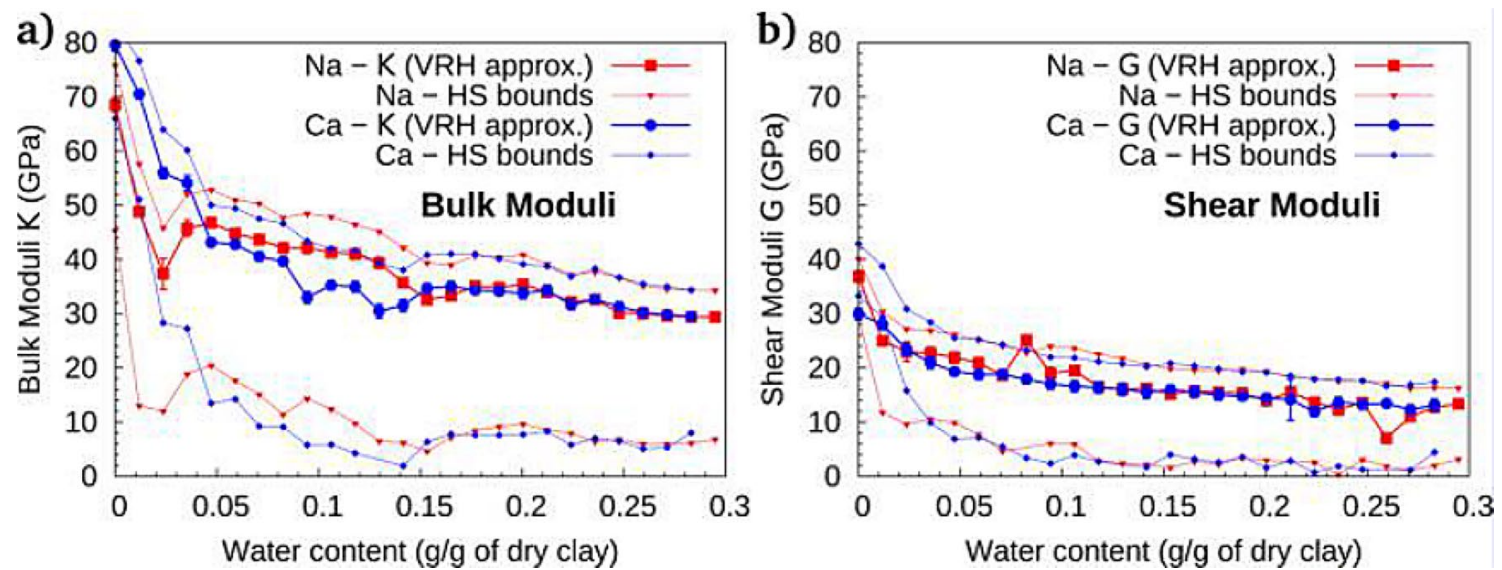

Fig. 14 Bulk modulus $\mathrm{K}(\mathbf{a})$ and shear modulus $\mathrm{G}(\mathbf{b})$ of anisotropic montmorillonite polycrystal at $300 \mathrm{~K}_{\text {with }} \mathrm{Na}^{+}$or $\mathrm{Ca}^{2+}$ interlayer cations as a function of water content (Carrier et al. 2014)

Ebrahimi et al. (2012) obtained similar results that led to the conclusion that clay mineral to be anisotropic in the transverse direction and only becomes isotropic after forming a one-layer hydrate. Additionally, Carrier et al. (2014) observed that in the dry state and at low water content, the $\mathrm{Ca}-\mathrm{Mt}$ was found to be stronger than the $\mathrm{Na}-\mathrm{Mt}$ along the $z$-direction.

As we have seen earlier, in any petroleum drilling operation with WBDF, we can expect a two-layer hydrate forming at the minimum. Additionally, clay minerals along the wall of a drill hole can have any orientation to the hole. Therefore, simulation studies like these are vital in finding molecules that will stabilize the wall and prevent it from collapsing.

\section{Effect of temperature}

Carrier et al. (2014) employed an elastic bath method to investigate the elastic properties of swelling $\mathrm{Na}-$ and $\mathrm{Ca}-\mathrm{Mt}$ at finite temperatures. The out-of-plane stiffness tensor coefficients were found to be very sensitive to temperature. When the temperature was increased from 0 to $300 \mathrm{~K}$, the $\mathrm{C}_{33}$ computed results differed by a factor of three, higher at $0 \mathrm{~K}$ and lower at $300 \mathrm{~K}$. In contrast, the in-plane coefficients were not very sensitive to temperature and water content. They observed a small linear change that could be explained by the geometric effect due to swelling.

\section{Effect of the normal force}

Schmidt et al. (2005) and later-on Katti et al. (2007) found out that applying external stress compressed $\mathrm{Na}-\mathrm{Mt}$ with more significant deformation in the interlayer than on the clay layers for stress ranging from 0 to $2.9 \mathrm{GPa}$ (Fig. 15). Most of the stress-deformation response for the dry and onelayer hydrate was linear and became nonlinear with increasing water content. They observed that increasing stress resulted in insignificant one-layer deformation. Still, when two and three water layers were introduced in the interlayer, abrupt deformation was discovered at a stress range of about
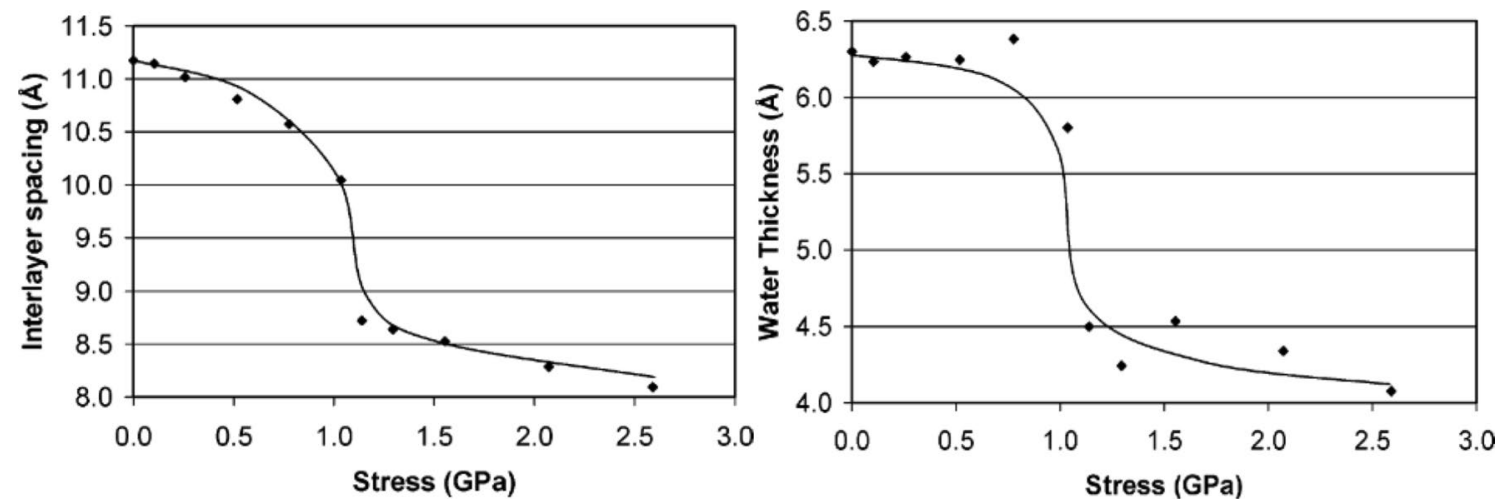

Fig. 15 Effect of normal force on Na-Mt interlayer spacing (L) and water thickness (R) (Schmidt et al. 2005) 
0.5-1 GPa. The two-layer was compressed into monolayer thickness, and the three-layer was subsequently compressed to a two-layer thickness.

Hydrocarbons reserves can be located anywhere between 3 and $8 \mathrm{~km}$ in the ground (Titiloye and Skipper 2001). Before drilling, the rock strength and the in situ rock stresses are in equilibrium. However, the balance is disturbed by the drilling process resulting in a potential borehole instability. Therefore, more attention needs to be paid to study the clay minerals' structural stability change in these extreme conditions.

\section{Inhibitor action on montmorillonite swelling}

The use of WBDF necessitates the addition of shale inhibitors in the drilling fluid. MD simulation methods have proven to be a great tool in improving our understanding of different molecules' inhibition mechanisms and predicting inherent features for designing suitable ones.

\section{Action of organic inhibitors}

Bains et al. (2001) studied clay-water interaction with ethylene glycol (EG) and polyethylene glycol 300 (PEG300, relative molecular mass 300 ) each in a separate simulation. They found that swelling inhibition is a function of concentration, as the EG performed well only at a very high concentration (>60\%). In contrast, the PEG300 can perform relatively well at a low concentration of about $6 \%$. Also, in their study, they have found that for improved and better performance, inhibitor molecules should possess well-defined hydrophobic regions with polar hydroxyl groups embedded in between. Additionally, the organic molecules should be a long linear chain with significant hydrophobic and hydrophilic areas. The hydrophobic areas will act as a seal to prevent water ingress during drilling operations, whereas the hydrophilic part will bind the $\mathrm{Na}^{+}$to the clay surface, preventing their hydration.

Suter et al. (2011) studied swelling inhibition of the cationic and polyether molecules often used in WBDF. They substituted interlayer cation with monocationic swelling inhibitors, tetramethylammonium (TMA), and tetraethylammonium (TEA) cations. With these molecules, the hydration energies reached bulk water levels at lower hydration states than with $\mathrm{Na}^{+}$, indicating swelling inhibition. Additionally, when analyzing their interlayer density profiles in the dry state, both cations were in a monolayer formation and resided near the clay surface's negatively charged sites. As the water content increased, the molecules stayed above charge sites, and the water molecules were located between cations. Suter et al. (2011) also investigated the di-cationic amine hexamethylenediamine
(HMDA) inhibition effect in Na-Mt interlayer, assuming a complete cation exchange. Basal spacing remained $13.0 \AA$ from the dry state up to water content of $75 \mathrm{mg} \mathrm{g}^{-1}$ clay and increased sharply to $15.2 \AA$ at a water content of $150 \mathrm{mg} \mathrm{g}^{-1}$ clay, which is a point where the hydration energies are similar to that of bulk water and above which there will be no more swelling. They also investigated polyether diamines PEG and PPG, and the hydration energy was found to be similar to that of the HMDA. However, the much lower water content of about $75 \mathrm{mg} \mathrm{g}^{-1}$ was required for the hydration energy to reach bulk water suggesting a better swelling inhibition than the HMDA.

WBDF, in the past few decades, has increasingly been used in drilling for oil and gas because of its low cost and being less environmentally pollutant. Therefore, more simulations should be done to improve the efficiency of swelling inhibitors. It is useful for reducing the drilling costs and the environment, especially when organic inhibitors are used.

\section{Action of inorganic inhibitors}

\section{Role of the cation}

The addition of inorganic molecules in hydrated clay mineral interlayer lowers cation coordination to water reducing the mineral swelling due to cations hydration (Jiafang et al. 2014). The inorganic salts addition promotes cation exchange by introducing foreign cations in the interlayer region of hydrated Mt. For instance, $\mathrm{Na}^{+}$'s exchange by $\mathrm{K}^{+}$from $\mathrm{KCl}$ addition will introduce $\mathrm{K}^{+}$that has lower hydration energy than $\mathrm{Na}^{+}$(Fig. 16).

Similar results were obtained by Camara et al. (2019), where they studied the influence of different inorganic salts addition in $\mathrm{Na}-\mathrm{Mt}$ interlayer. $\mathrm{NH}_{4} \mathrm{Cl}$ addition performed better in reducing basal spacing increase compared to the addition of $\mathrm{AlCl}_{3}, \mathrm{MgCl}_{2}$, and $\mathrm{FeCl}_{3}$ (Fig. 17). Additionally, inorganic salt addition into $\mathrm{Mt}$ interlayer increases ionic interactions between interlayer particles themselves and the clay sheet's minerals. This increase in coulombic interactions improves the crystal's elastic strength (Jiafang et al. 2014).

Despite being less pollutant compared to other drilling fluids, high concentration of inhibitors used with WBDF (e.g., $\mathrm{K}^{+}$from $\mathrm{KCl}$ ) has raised concern, particularly now that we see an increase in offshore operations (Fraser 2014; Olsgard and Gray 1995; Pappworth and Caudle 2016; Zhang et al. 2016a). Therefore, we need more MD simulations that focus on finding organic cations. 

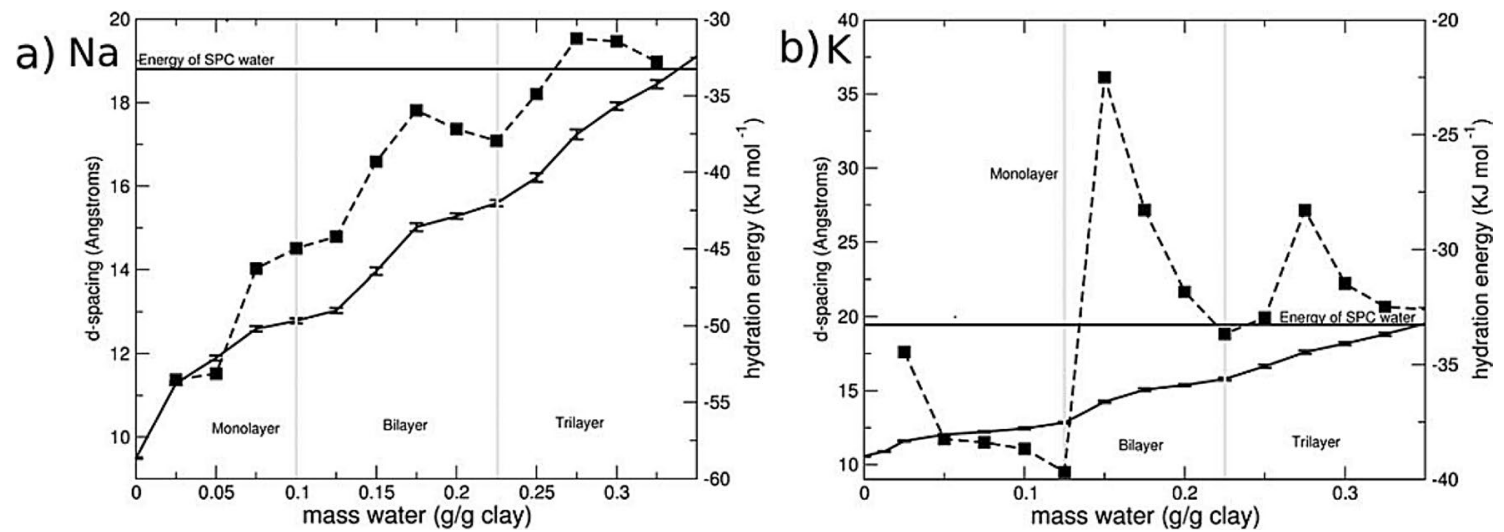

Fig. 16 The d-spacings (solid lines, left vertical axis) and discrete hydration energies (dashed lines, right vertical axis) of Wyoming montmorillonite with $\mathrm{Na}^{+}$as the majority counterion (a) and with $\mathrm{K}^{+}$as the only cation (b) (Suter et al. 2011)
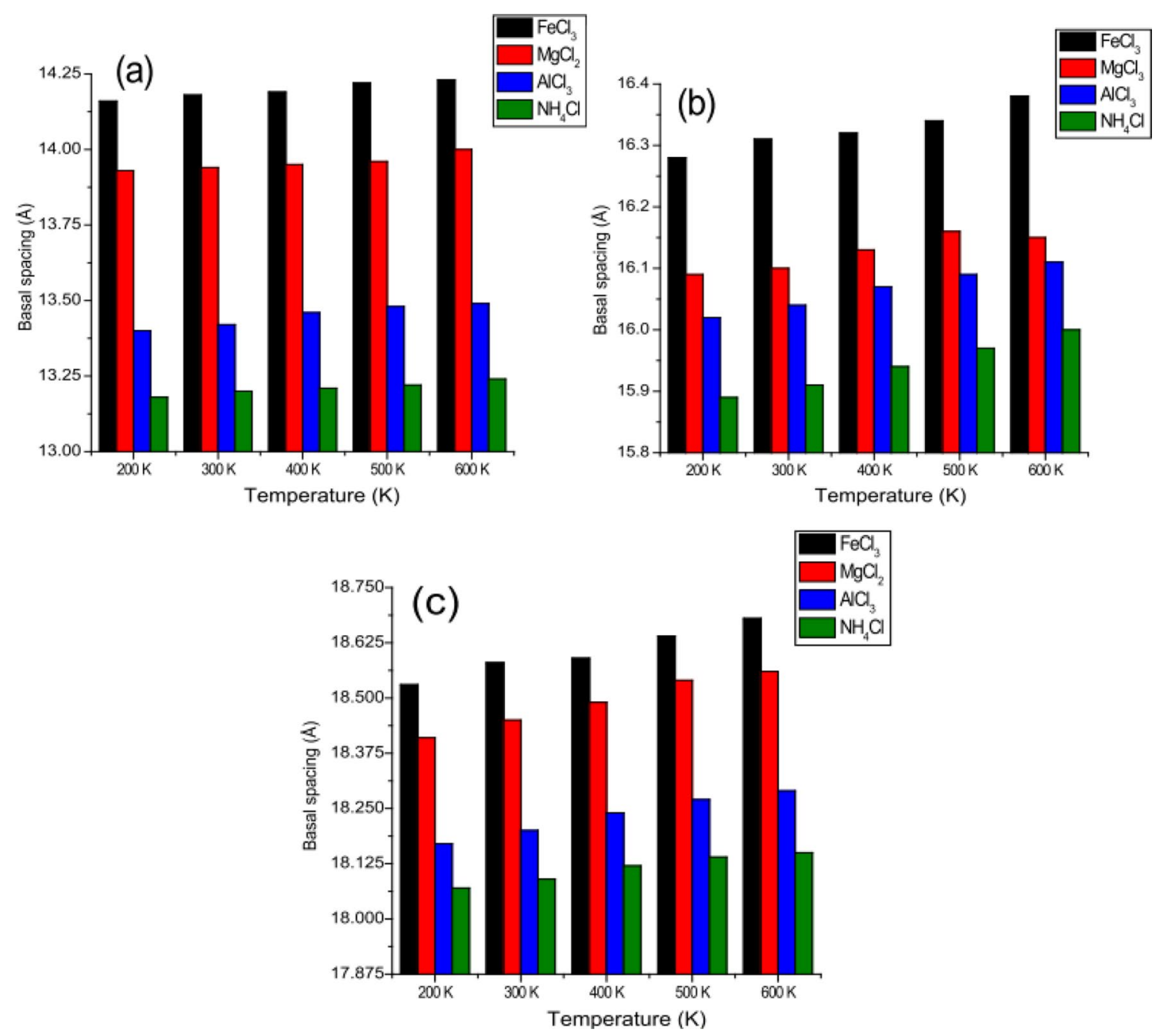

Fig. 17 Basal spacing changes with temperature for different layered $\mathrm{Na}-\mathrm{Mt}$ after adding inorganic salts; a-c represent one, two, and three hydration layers, respectively (Camara et al. 2019) 


\section{Role of the anion}

The negatively charged particles are not likely to belong in the interlayer space of clay minerals. The work of Tournassat et al. (2016) has shown that the $\mathrm{Cl}^{-}$is going to be excluded from the interlayer and will be partially banned from entering nanopores of clay minerals. When the water content was increased gradually to five water layers, $\mathrm{Cl}^{-}$ions had access to the interlayer only from three to five-layer hydrates. Another simulation that reported similar results was by Hedström and Karnland (2012). These results seem to suggest that anions have limited access to the interlayer space. Therefore, at low water contents, the anions in WBDF simply serve as carriers of the cations, and once the dissociation occurs, the anions remain in the bulk phase. More MD simulations can be conducted on anion's role in swelling inhibition when adsorbed on the surface and edges of clays as well as when they are (even if it is for a short time) in the clay nanopores.

\section{Conclusions}

This article reviewed MD simulation works on clay-water interactions to investigate clay swelling mechanisms and the inhibitors' actions. The review presented the key insights needed to quantify the observations and understand the mechanisms involved in clay swelling and its inhibition for the petroleum drilling application. In this final section, some of the things not addressed by documented literature are pointed out.

1. In a petroleum drilling operation, a mixture of bentonite and different chemicals are usually used to prepare WBDF. Since mixing different chemicals can have a synergistic effect, it will be interesting to simulate inhibitor and other vital ingredients of the WBDF interactions with clays. Some time ago, due to less computer power, such computationally expensive systems could not be studied. However, there have been considerable advancements in computer hardware recently. Therefore, systems that consider the impact of the presence of other chemicals can be investigated.

2. Different MD simulations in the literature use different models to represent water in clay-water interaction. Some of these works have reported discrepancies when other water-based models are used. However, no clear explanations are given on the decision criteria for choosing any particular model. Following the work of Ferrage et al. (2011), it will be much proper for future simulations to adopt models that best fit the experimental values. Apart from simplifying computations, there is no other meaningful reason given for making a specific choice.

3. There are many contrasting findings on the influence of layer charge and charge location on the swelling of Mt. These differences necessitate a more in-depth analysis of the atomic-scale interactions to quantify the observations and explore the involved mechanisms more accurately.

4. Most MD simulation literature does not analyze Mt swelling as a function of inhibitor concentration. Therefore, it will be captivating to know the optimum concentration for the best inhibitor performance. Besides, knowing this is extremely helpful as it can reduce the costs of drilling and save the environment if it is found that low concentration can achieve a similar effect as high concentration.

5. Finally, to make the MD simulations closely resemble clay-water interactions in real life. Instead of using the non-reactive force fields (e.g., Clayff), it will be compelling to investigate the clay-water-inhibitor interaction using a reactive force field, such as that by Chenoweth et al. (2009).

Acknowledgements The author acknowledges a scholarship from the Campus France International, Tanzania Office.

\section{Compliance with ethical standards}

Conflict of interest There is no conflict of interest.

Open Access This article is licensed under a Creative Commons Attribution 4.0 International License, which permits use, sharing, adaptation, distribution and reproduction in any medium or format, as long as you give appropriate credit to the original author(s) and the source, provide a link to the Creative Commons licence, and indicate if changes were made. The images or other third party material in this article are included in the article's Creative Commons licence, unless indicated otherwise in a credit line to the material. If material is not included in the article's Creative Commons licence and your intended use is not permitted by statutory regulation or exceeds the permitted use, you will need to obtain permission directly from the copyright holder. To view a copy of this licence, visit http://creativecommons.org/licenses/by/4.0/.

\section{References}

Al-Ani T, Sarapaa O (2008) Clay and clay mineralogy. Helsinki Anderson RL, Ratcliffe I, Greenwell HC, Williams PA, Cliffe S, Coveney PV (2010) Clay swelling: a challenge in the oilfield. Earth-Sci Rev 98:201-216. https://doi.org/10.1016/j.earsc irev.2009.11.003

Annabi-Bergaya F (2006) Handbook of clay science, 1st edn. Elsevier, Amsterdam

Ars F, Rios R (2017) Decommissioning: a call for a new approach. Proc Annu Offshore Technol Conf 4:2843-2849. https://doi. org/10.4043/27717-ms

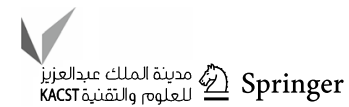


Bains AS, Boek ES, Coveney PV, Williams SJ, Akbar MV (2001) Molecular modelling of the mechanism of action of organic clay-swelling inhibitors. Mol Simul 26:101-145. https://doi. org/10.1080/08927020108023012

Berendsen HJC, Postma JPM, van Gunsteren WF, Hermans J (1981) Interaction models for water in relation to protein hydration. In: Pullman B (ed) Intermolecular Forces. D. Reidel Publishing Company, pp 331-342. https://doi.org/10.1007/978-94-015-7658-1

Berendsen HJC, Grigera JR, Straatsma TP (1987) The missing term in effective pair potentials. J Phys Chem 91:6269-6271. https://doi. org/10.1021/j100308a038

Bjørlykke K (1998) Clay mineral diagenesis in sedimentary basins: a key to the prediction of rock properties. examples from the North Sea Basin. Clay Miner 33:15-34. https://doi.org/10.1180/claym in.1998.033.1.03

Boek ES, Coveney PV, Skipper NT (1995a) Molecular modeling of clay hydration: a study of hysteresis loops in the swelling curves of sodium montmorillonites. Langmuir 11:4629-4631. https://doi. org/10.1021/la00012a008

Boek ES, Coveney PV, Skipper NT (1995b) Monte Carlo molecular modeling studies of hydrated $\mathrm{Li}-, \mathrm{Na}-$, and $\mathrm{K}$-smectites: understanding the role of potassium as a clay swelling inhibitor. J Am Chem Soc 117:12608-12617. https://doi.org/10.1021/ja00155a02 5

Bourg I, Sposito G (2010) Connecting the molecular scale to the continuum scale for diffusion processes in smectite-rich porous media. Environ Sci Technol 44:2085-2091. https://doi. org/10.1021/es903645a

Brown KM, Poeppe D, Josh M, Sample J, Even E, Saffer D, Tobin H, Hirose T, Kulongoski JT, Toczko S, Maeda L (2017) The action of water films at $\AA$-scales in the Earth: implications for the Nankai subduction system. Earth Planet Sci Lett 463:266-276. https://doi. org/10.1016/j.epsl.2016.12.042

Camara M, Liao H, Xu J, Ding T, Swai R, Zhang J (2019) Effects of inorganic salts addition on Na-montmorillonite clay at high temperature and high pressure: insights from molecular dynamics simulation. J Mater Sci Eng 8:1-13

Carrier B, Vandamme M, Pellenq RJM, Damme H Van, Van Damme H (2014) Elastic properties of swelling clay particles at finite temperature upon hydration. J Phys Chem C 118:8933-8943. https:// doi.org/10.1021/jp412160e

Carrier B, Vandamme M, Pellenq R, Damme H Van (2017) Measurement of mechanical properties of thin clay films and comparison with molecular simulations. Adv Lab Test Model Soils Shales. https://doi.org/10.1007/978-3-319-52773-4

Chang FRC, Skipper NT, Sposito G (1995) Computer simulation of interlayer molecular structure in sodium montmorillonite hydrates. Langmuir 11:2734-2741. https://doi.org/10.1021/la00007a064

Chang F-RC, Skipper NT, Sposito G (1997) Monte Carlo and molecular dynamics simulations of interfacial structure in lithiummontmorillonite hydrates. Langmuir 13:2074-2082. https://doi. org/10.1021/la9603176

Chang F-RC, Skipper NT, Sposito G (1998) Monte Carlo and molecular dynamics simulations of electrical double-layer structure in potassium-montmorillonite hydrates. Langmuir 7463:1201-1207. https://doi.org/10.1021/la9704720

Chavez-Paez M, dePablo L (2001) Monte Carlo simulations of Ca-montmorillonite hydrates. J Chem Phys. https://doi. org/10.1063/1.1374536

Chávez-Páez M, DePablo L, DePablo JJ (2001) Monte Carlo simulations of Ca-montmorillonite hydrates. J Chem Phys 114:1094810953. https://doi.org/10.1063/1.1374536

Chen G, Chenevert ME, Sharma MM, Yu M (2003) A study of wellbore stability in shales including poroelastic, chemical, and thermal effects. J Pet Sci Eng 38:167-176. https://doi.org/10.1016/ S0920-4105(03)00030-5
Chenoweth K, Van Duin ACT, Goddard WA (2009) The ReaxFF monte carlo reactive dynamics method for predicting atomistic structures of disordered Ceramics: application to the $\mathrm{Mo}_{3} \mathrm{VO}_{x}$ catalyst. Angew Chemie Int Ed 48:7630-7634. https://doi.org/10.1002/ anie. 200902574

Cygan RT, Liang J-J, Kalinichev AG (2004) Molecular models of hydroxide, oxyhydroxide, and clay phases and the development of a general force field. J Phys Chem B 108:1255-1266. https:// doi.org/10.1021/jp0363287

Ebrahimi D, Pellenq RJ, Whittle AJ (2012) Nanoscale elastic properties of montmorillonite upon water adsorption. Langmuir 28:16855-16863. https://doi.org/10.1021/la302997g

Ferrage E, Sakharov BA, Michot LJ, Delville A, Bauer A, Lanson B, Grangeon S, Frapper G, Jiménez-Ruiz M, Cuello GJ (2011) Hydration properties and interlayer organization of water and ions in synthetic na-smectite with tetrahedral layer charge. Part 2. Toward a precise coupling between molecular simulations and diffraction data. J Phys Chem C 115:1867-1881. https:// doi.org/10.1021/jp105128r

Fink JK (2012) Petroleum Engineer's guide to oil field chemicals and fluids, 1st edn. Gulf Professional Publishing, New York

Fraser GS (2014) Impacts of offshore oil and gas development on marine wildlife resources. In: Gates J, Trauger D, Czech B (eds), Peak oil, economic growth and wildlife conservation. Springer, New York, pp 191-217. https://doi. org/10.1007/978-1-4939-1954-3

Frenkel D, Smit B (2002) Understanding molecular simulation from algorithms to applications. Academic Press, Great Britain

Georg K, Sergey CV, Tres T (2008) Diffusion of Na and Cs in Montmorillonite. Clays Clay Miner 56:190-206. https://doi. org/10.1346/CCMN.2008.0560205

Gholami R, Elochukwu H, Fakhari N, Sarmadivaleh M (2018) A review on borehole instability in active shale formations: interactions, mechanisms and inhibitors. Earth-Sci Rev 177:1-13. https://doi.org/10.1016/j.earscirev.2017.11.002

González MA (2011) Force fields and molecular dynamics simulations. Société Française la Neutron 12:169-200. https://doi. org/10.1051/sfn/201112009Force

Greathouse J, Sposito G (1998) Monte Carlo and molecular dynamics studies of interlayer structure in $\mathrm{Li}\left(\mathrm{H}_{2} \mathrm{O}\right)_{3}$-smectites. J Phys Chem B 102:2406-2414. https://doi.org/10.1021/jp980120h

Hedström M, Karnland O (2012) Donnan equilibrium in Na-montmorillonite from a molecular dynamics perspective. Geochim Cosmochim Acta 77:266-274. https://doi.org/10.1016/j. gca.2011.11.007

Hensen EJM, Smit B (2002) Why clays swell. J Phys Chem B 106:12664-12667. https://doi.org/10.1021/jp0264883

Hensen EJM, Tambach TJ, Bliek A, Smit B (2001) Adsorption isotherms of water in Li-, Na-, and $\mathrm{K}$ - montmorillonite by molecular simulation. J Chem Phys 115:3322-3329. https:// doi.org/10.1063/1.1386436

Hodder M, Cliffe S, Williams P, Coveney P, Greenwell C (2010) Clay swelling inhibitors-computer design and validation. Am Assoc Drill Eng, pp 1-6

Hower J, Eslinger EV, Hower ME, Perry EA (1976) Mechanism of burial metamorphism of argillaceous sediment : 1. Mineralogical and chemical evidence. Geol Soc Am 87:725-737. https://doi.org/10.1130/0016-7606(1976)87\%3c725:MOBMO A\%3e2.0.CO; 2

Iltis M, Didider G, Lareal P (1982) Comparison of the inhibitory action of $\mathrm{KCI}$ and guanidine hydrochloride solutions on montmorillonite swelling. Soc Pet Eng 2:514-522. https://doi. org/10.2118/9092-PA

Jiafang X, Hongjun S, Xianwei F, Zhongfu S, Xiaodi L (2014) Molecular simulation for inorganic salts inhibition mechanism on 
montmorillonite hydration. Acta Pet Sin 35:377-384. https://doi. org/10.7623/syxb201402021

Jorgensen WL, Madura JD (1983) Solvation and Conformation of Methanol in Water. J Am Chem Soc 105:1407-1413. https://doi. org/10.1021/ja00344a001

Katti DR, Schmidt SR, Ghosh P, Katti KS (2007) Molecular modeling of the mechanical behavior and interactions in dry and slightly hydrated sodium montmorillonite interlayer. Can Geotech J 44:425-435. https://doi.org/10.1139/T06-127

Katti DR, Matar MI, Katti KS, Amarasinghe PM (2009) Multiscale modeling of swelling clays: a computational and experimental approach. KSCE J Civ Eng 13:243-255. https://doi.org/10.1007/ s12205-009-0243-0

Kaufhold S, Baille W, Schanz T, Dohrmann R (2015) About differences of swelling pressure-dry density relations of compacted bentonites. Appl Clay Sci 107:52-61. https://doi.org/10.1016/j. clay.2015.02.002

Kenji T, Hirohisa Y, Hiromoto N (2000) Stepwise hydration of highquality synthetic smectite with various cations. Clays Clay Miner 48:400-404

Laird DA (2006) Influence of layer charge on swelling of smectites. Appl Clay Sci 34:74-87. https://doi.org/10.1016/j. clay.2006.01.009

Li Y, Kumar A, Nair N, Kadoura A, Yang Y, Sun S (2019) Molecular simulation study of montmorillonite in contact with water. Ind Eng Chem Res 58:1396-1403. https://doi.org/10.1021/acs. iecr.8b05125

Liu X, Lu X, Wang R, Zhou H (2008) Effects of layer-charge distribution on the thermodynamic and microscopic properties of Cssmectite. Geochim Cosmochim Acta 72:1837-1847. https://doi. org/10.1016/j.gca.2008.01.028

Marry V, Turq P, Cartailler T, Levesque D (2002) Microscopic simulation of structure and dynamics of water and counterions in a monohydrated montmorillonite. J Chem Phys. https://doi. org/10.1063/1.1493186

Mooney RW, Keenan AG, Wood LA (1952) Adsorption of water vapor by montmorillonite. II. Effect of exchangeable ions and lattice swelling as measured by X-ray diffraction. J Am Chem Soc 74:1371-1374. https://doi.org/10.1021/ja01126a002

Moussa C, Xu J, Wang X, Zhang J, Chen Z, Li X (2017) Molecular dynamics simulation of hydrated Na-montmorillonite with inorganic salts addition at high temperature and high pressure. Appl Clay Sci 146:206-215. https://doi.org/10.1016/j.clay.2017.05.045

Na P, Zhang F (2006) Molecular dynamics simulation of Na-montmorillonite and $\mathrm{Na} / \mathrm{Mg}$-montmorillonite hydrates. Acta Physico-Chim Sin. 22:1137-1142. https://doi.org/10.1016/s1872 $-1508(06) 60053-3$

Nehdi ML (2014) Clay in cement-based materials: critical overview of state-of-the-art. Constr Build Mater 51:372-382. https://doi. org/10.1016/j.conbuildmat.2013.10.059

Neumann M (1985) The dielectric constant of water. Computer simulations with the MCY potential. J Chem Phys 82:5663-5672. https ://doi.org/10.1063/1.448553

Ngouana W, Brice F, Kalinichev AG (2014) Structural arrangements of isomorphic substitutions in smectites : molecular simulation of the swelling properties, interlayer structure, and dynamics of hydrated Cs-montmorillonite revisited with new clay models. J Phys Chem C 118: 12758-12773. https://doi.org/10.1021/jp500538z

Norrish BYK (1954) The swelling of Montmorillonite. Discuss Faraday Soc. https://doi.org/10.1039/DF9541800120

Olphen H Van (1962) Compaction of clay sediments in the range of molecular particle distances. Clay Clay Miner 11:178-187. https ://doi.org/10.1346/CCMN.1962.0110116

Olsgard F, Gray JS (1995) A comprehensive analysis of the effects of offshore oil and gas exploration and production on the benthic communities of the Norwegian continental shelf. Mar Ecol Prog Ser 122(1):277-306

Pappworth SSR, Caudle DD (2016) Drilling and production discharges in the marine environment. In: Orszulik S (ed) Environmental technology in the oil industry. Springer, Cham, pp 221-256. https ://doi.org/10.1007/978-3-319-24334-4

Posner, A.M., Quirk, J.P., Prescott, J.A., 1963. The adsorption of water from concentrated electrolyte solutions by $\mathrm{m}$ ontm orillonite and illite. Proc R Soc Math Phys Sci 278:35-56. https:// doi.org/10.1098/rspa.1964.0044

Rappe AK, Casewit CJ, Colwell KS, Goddard WA, Skiff WM (1992) UFF, a full periodic table force field for molecular mechanics and molecular dynamics simulations. J Am Chem Soc 114:1002410035. https://doi.org/10.1021/ja00051a040

Ray SS (2013) An overview of pure and organically modified clays. In: Clay-containing polymer nanocomposites. Elsevier, Amsterdam, pp 1-24. https://doi.org/10.1016/B978-0-444-59437-2.00001-6

Roberts VA, Dauber-osguthorpe P, David JO, Wolff J, Genest M, Hagler AT (1988) Structure and energetics of ligand binding to proteins : Escherichia coli dihydrofolate reductase-trimethoprim, a drug-receptor system. Proteins 47:31-47. https://doi. org/10.1002/prot.340040106

Salles F, Devautour-Vinot S, Bildstein O, Jullien M, Maurin G, Giuntini JC, Douillard JM, Damme H Van (2008) Ionic mobility and hydration energies in montmorillonite clay. J Phys Chem C 112:1400114009. https://doi.org/10.1021/jp710976g

Sayers CM, den Boer LD (2016) The elastic anisotropy of clay minerals. Geophysics. https://doi.org/10.1190/geo2016-0005.1

Schmidt SR, Katti DR, Ghosh P, Katti KS (2005) Evolution of mechanical response of sodium montmorillonite interlayer with increasing hydration by molecular dynamics. Langmuir 21:8069-8076. https://doi.org/10.1021/la050615f

Seppälä A, Puhakka E, Olin M (2016) Effect of layer charge on the crystalline swelling of $\mathrm{Na}+, \mathrm{K}+$ and $\mathrm{Ca} 2+$ montmorillonites: DFT and molecular dynamics studies. Clay Miner 51:197-211. https://doi.org/10.1180/claymin.2016.051.2.07

Shroll RM, Smith DE (1999) Molecular dynamics simulations in the grand canonical ensemble: application to clay mineral swelling. J Chem Phys 111:9025-9033. https://doi.org/10.1063/1.480245

Sun L, Tanskanen JT, Hirvi JT, Kasa S, Schatz T, Pakkanen TA (2015) Molecular dynamics study of montmorillonite crystalline swelling: roles of interlayer cation species and water content. Chem Phys 455:23-31. https://doi.org/10.1016/j.chemphys.2015.04.005

Sun L, Ling CY, Lavikainen LP, Hirvi JT, Kasa S, Pakkanen TA (2016) Influence of layer charge and charge location on the swelling pressure of dioctahedral smectites. Chem Phys 473:40-45. https://doi. org/10.1016/j.chemphys.2016.05.002

Suter JL, Coveney PV, Anderson RL, Greenwell HC, Cliffe S (2011) Rule based design of clay-swelling inhibitors. Energy Environ Sci 4:4572-4586. https://doi.org/10.1039/c1ee01280k

Suter JL, Kabalan L, Khader M, Coveney PV (2015) Ab initio molecular dynamics study of the interlayer and micropore structure of aqueous montmorillonite clays. Geochim Cosmochim Acta 169:17-29. https://doi.org/10.1016/j.gca.2015.07.013

Tambach TJ, Hensen EJM, Smit B (2004) Molecular simulations of swelling clay minerals. J Phys Chem B 108:7586-7596. https:// doi.org/10.1021/jp049799h

Tambach TJ, Bolhuis PG, Hensen EJMM, Smit B (2006) Hysteresis in clay swelling induced by hydrogen bonding: accurate prediction of swelling states. Langmuir 22:1223-1234. https://doi.org/10.1021/ la051367q

Tan CP, Richards BG, Rahman SS (1996) SPE 36971 managing physico-chemical mechanism wellbore instability in shales with the chemical potential. In: SPE international conference exhibition

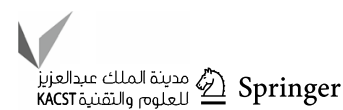


Tao L, Xiao-Feng T, Yu Z, Tao G (2010) Swelling of K+, Na+ and $\mathrm{Ca} 2+-$ montmorillonites and hydration of interlayer cations: a molecular dynamics simulation. Chin Phys B 19:109101-109107. https://doi.org/10.1088/1674-1056/19/10/109101

Taylor K, Smith T (1986) The engineering geology of clay minerals: swelling, shrinking and mudrock breakdown. Clay Miner 21: 235-260. https://doi.org/10.1180/claymin.1986.021.3.01

Teich-McGoldrick SL, Greathouse JA, Jové-Colón CF, Cygan RT (2015) Swelling properties of montmorillonite and Beidellite clay minerals from molecular simulation: comparison of temperature, interlayer cation, and charge location effects. J Phys Chem C 119:20880-20891. https://doi.org/10.1021/acs.jpcc.5b03253

Titiloye JO, Skipper NT (2001) Molecular dynamics simulation of methane in sodium montmorillonite clay hydrates at elevated pressures and temperatures. Mol Phys 99:899-906. https://doi. org/10.1080/00268970010028863

Tournassat C, Bourg IC, Holmboe M, Sposito G, Steefel CI (2016) Molecular dynamics simulations of anion exclusion in clay interlayer nanopores. Clays Clay Miner 64:374-388. https://doi. org/10.1346/CCMN.2016.0640403

van Oort E (2003) On the physical and chemical stability of shales. J Pet Sci Eng 38:213-235. https://doi.org/10.1016/S0920 $-4105(03) 00034-2$

Wang HM (2010) Rethinking of shale swelling based on interesting test results. Am Rock Mech Assoc J 10

Whitley HD, Smith DE (2004) Free energy, energy, and entropy of swelling in $\mathrm{Cs}-, \mathrm{Na}-$, and $\mathrm{Sr}-$ montmorillonite clays. J Chem Phys 120:5387-5395. https://doi.org/10.1063/1.1648013

Wu L, Liao L, Lv G (2015) Influence of interlayer cations on organic intercalation of montmorillonite. J Colloid Interface Sci 454:1-7. https://doi.org/10.1016/j.jcis.2015.04.021

Xu J, Camara M, Liu J, Peng L, Zhang R, Ding T (2017) Molecular dynamics study of the swelling patterns of $\mathrm{Na} / \mathrm{Cs}-, \mathrm{Na} / \mathrm{Mg}-$ montmorillonites and hydration of interlayer cations. Mol Simul 43:575-589. https://doi.org/10.1080/08927022.2016.1274982

Yang G, Neretnieks I, Holmboe M (2017) Atomistic simulations of cation hydration in sodium and calcium montmorillonite nanopores. J Chem Phys. https://doi.org/10.1063/1.4992001

Yi H, Jia F, Zhao Y, Wang W, Song S, Li H, Liu C (2018) Surface wettability of montmorillonite $\left(\begin{array}{lll}0 & 0 & 1\end{array}\right)$ surface as affected by surface charge and exchangeable cations: a molecular dynamic study. Appl Surf Sci 459:148-154. https://doi.org/10.1016/j.apsus c.2018.07.216

Zhang L, Lu X, Liu X, Zhou J, Zhou H (2014) Hydration and mobility of interlayer ions of (Nax, Cay)—montmorillonite: a molecular dynamics study. J Phys Chem C 118: 29811-29821. https://doi. org/10.1021/jp508427c

Zhang C, Brom R, Smith JP, Getliff J, Smith JP (2016a) Improving environmental performance by sharing information on offshore drilling discharge environmental science and drill cuttings treatment. Soc Pet Eng. https://doi.org/10.2118/179271-MS

Zhang X, Yi H, Zhao Y, Min F, Song S (2016b) Study on the differences of $\mathrm{Na}$ - and $\mathrm{Ca}$-montmorillonites in crystalline swelling regime through molecular dynamics simulation. Adv Powder Technol 27:779-785. https://doi.org/10.1016/j.apt.2016.03.005

Zhang WN, Hu HX, Li XC, Fang ZM (2017) Changes in micromechanical properties of Na-montmorillonite caused by $\mathrm{CO}_{2} / \mathrm{H}_{2} \mathrm{O}$ sorption. Comput Mater Sci 129:178-183. https://doi.org/10.1016/j. commatsci.2016.12.024

Zhang Y, Gao S, Du X, Chen M, Jin Y (2019) Journal of Petroleum Science and Engineering Molecular dynamics simulation of strength weakening mechanism of deep shale. J Pet Sci Eng 181:106123. https://doi.org/10.1016/j.petrol.2019.05.074

Zheng Y, Zaoui A (2011) How water and counterions diffuse into the hydrated montmorillonite. Solid State Ionics 203:80-85. https:// doi.org/10.1016/j.ssi.2011.09.020

Zheng Y, Zaoui A (2018) Mechanical behavior in hydrated Na-montmorillonite clay. Phys A 505:582-590. https://doi.org/10.1016/j. physa.2018.03.093

Zhong H, Qiu Z, Huang W, Xie B, Wang W (2013) Bis (hexamethylene) triamine as potential shale inhibitor in water-based drilling fluid. Open Pet Eng J 6:49-56. https://doi.org/10.2174/18748 34101306010049

Publisher's Note Springer Nature remains neutral with regard to jurisdictional claims in published maps and institutional affiliations. 